\title{
Size of the treatment effect on cognition of cholinesterase inhibition in Alzheimer's disease
}

\section{K Rockwood}

J Neurol Neurosurg Psychiatry 2004;75:677-685. doi: 10.1136/jnnp.2003.029074

Correspondence to:

K Rockwood, Centre for Health Care of the Elderly, 5955 Veterans' Memorial Lane, Suite 1421, Halifax, Nova Scotia, Canada B3H 2El; kenneth.rockwood@ dal.co

Received 2 October 2003 In revised form

5 December 2003

Accepted 21 January 2004
Background: Six cholinesterase inhibitors (ChEls) have been tested in people with Alzheimer's disease, using methods currently required for regulatory approval. The clinical importance of their treatment effects is controversial.

Objective: To determine whether cholinesterase inhibition produces treatment effects in Alzheimer's disease that are large enough to be clinically detectable.

Methods: Overview analysis of published trials of ChEls in which the Alzheimer's Disease Assessment Scale-Cognitive Subscale (ADAS-Cog) and a global clinical measure were primary outcomes. Two quantitative summary measures of the treatment effect (Cohen's $d$ and the standardised response mean (SRM)) were calculated and presented as funnel plots. Observed cases analyses and intention to treat (ITT) with the last observation carried forward (LOCF) analyses were compared.

Results: The median Cohen's d effect sizes (ES) using ITT samples with LOCF for the ADAS-Cog were: low dose of a $\mathrm{ChEl}$ ( $\mathrm{n}=8$ studies) median $\mathrm{ES}=0.15$, range $=0.03-0.22$; medium dose $(n=13)$ median $\mathrm{ES}=0.23$, range $=0.12-0.29$; high dose $(\mathrm{n}=9)$ median $\mathrm{ES}=0.28$, range $=0.01-0.31$. In general, the $\mathrm{ES}$ were larger when calculated as SRMs (for example, high dose ChEl studies, median $S R M=0.47$; range $=0.30-0.63$ ) and highest in the observed cases analyses (for example, high dose median $\mathrm{SRM}=0.56$, range $=0.35-0.78$ ).

Global clinical scales produced similar estimates of ES (for example, high dose ChEI, ITT/LOCF median Cohen's $d=0.29$, range $=0.20-0.47)$.

Conclusions: ChEls produce small-moderate effect sizes in clinical trials which are reproducible and demonstrate a dose response. Better descriptions of the patterns of treatment response are needed to guide individual patient decisions about the effectiveness of treatment, but group effects are evident and appear large enough to be clinically detectable.
A lthough cholinesterase inhibitors (ChEIs) have been used for several years to treat Alzheimer's disease (AD), scepticism about their effectiveness persists. Many trials are short, the outcome measures are problematic, trials patients are generally healthier than most with the disease, and the treatment effects seem small. ${ }^{1-12}$ Moreover, there is concern about how the data have been analysed..$^{13}$ Given that decline can be expected even in short trials, and that ChEIs engender more side effects than placebos, intention to treat (ITT) analyses that employ a last observation carried forward (LOCF) method of handling missing data are suspect. Briefly, the concern is about so-called dropout bias, ${ }^{13}$ which occurs when patients who withdraw have systematically different outcomes than those who do not. While it is easy to imagine circumstances under which an LOCF analysis would be conservative-for example, if patients actively treated withdraw before they can recover from their illness, in the setting of $\mathrm{AD}$ trials, dropout bias could actually favour treatment. This would be the case if patients on active treatment more often withdrew early, due to side effects and before they had a chance to decline, whereas patients on placebo withdrew late and more often because of inefficacy. In consequence, LOCF analyses could actually compare patients on treatment with better scores with patients on placebo with worse scores.

Concern has also been expressed about the varying mixes of mildly and moderately impaired patients in the trials. ${ }^{12}$ As moderately impaired patients decline more quickly than do mildly impaired ones, ${ }^{14}{ }^{15}$ any treatment effect is likely to be more demonstrable with that group. Indeed, it has been demonstrated that the rate of progression of dementia predicts the response to cholinesterase inhibition. ${ }^{16}$ Thus, from the standpoint of interpreting clinical meaningfulness, using trial data based largely on patients with moderately severe dementia to counsel patients with mild dementia is problematic.

Attention also has been drawn to the difficulty in generalising to daily clinical practice data from clinical trials carried out for regulatory purposes..$^{1-3}$ The outcome measures used to evaluate ChEIs are not much used in clinical practice. The primary outcomes usually have been the Alzheimer's Disease Assessment Scale-Cognitive Subscale (ADAS-Cog) $)^{17}$ and a global clinical measure, typically the Clinician's Interview-Based Impression of Change Plus Caregiver Input (CIBIC-Plus). Tests such as the ADAS-Cog and CIBIC-Plus are seen as surrogate measures compared with "harder" measures, such as a delay in institutionalisation. The Cochrane Collaboration review of donepezil, for example, concluded that "the practical importance of these changes [in the ADAS-Cog] to patients and carers is unclear". Even though the CIBIC-Plus scores "clearly show some impact on global clinical states ..." "the rating scale is crude and difficult to interpret". ${ }^{1}$

This paper seeks to better understand the clinical meaningfulness of ChEIs in $\mathrm{AD}$ from the published data. It follows

Abbreviations: $A D$, Alzheimer's disease; ADAS-Cog, Alzheimer's Disease Assessment Scale-Cognitive Subscale; ChEls, cholinesterase inhibitors; CIBIC-Plus, Clinician's Interview-Based Impression of Change Plus Caregiver Input; ITT, intention to treat; LOCF, last observation carried forward; OC, observed cases; SRM, standardised response mean 


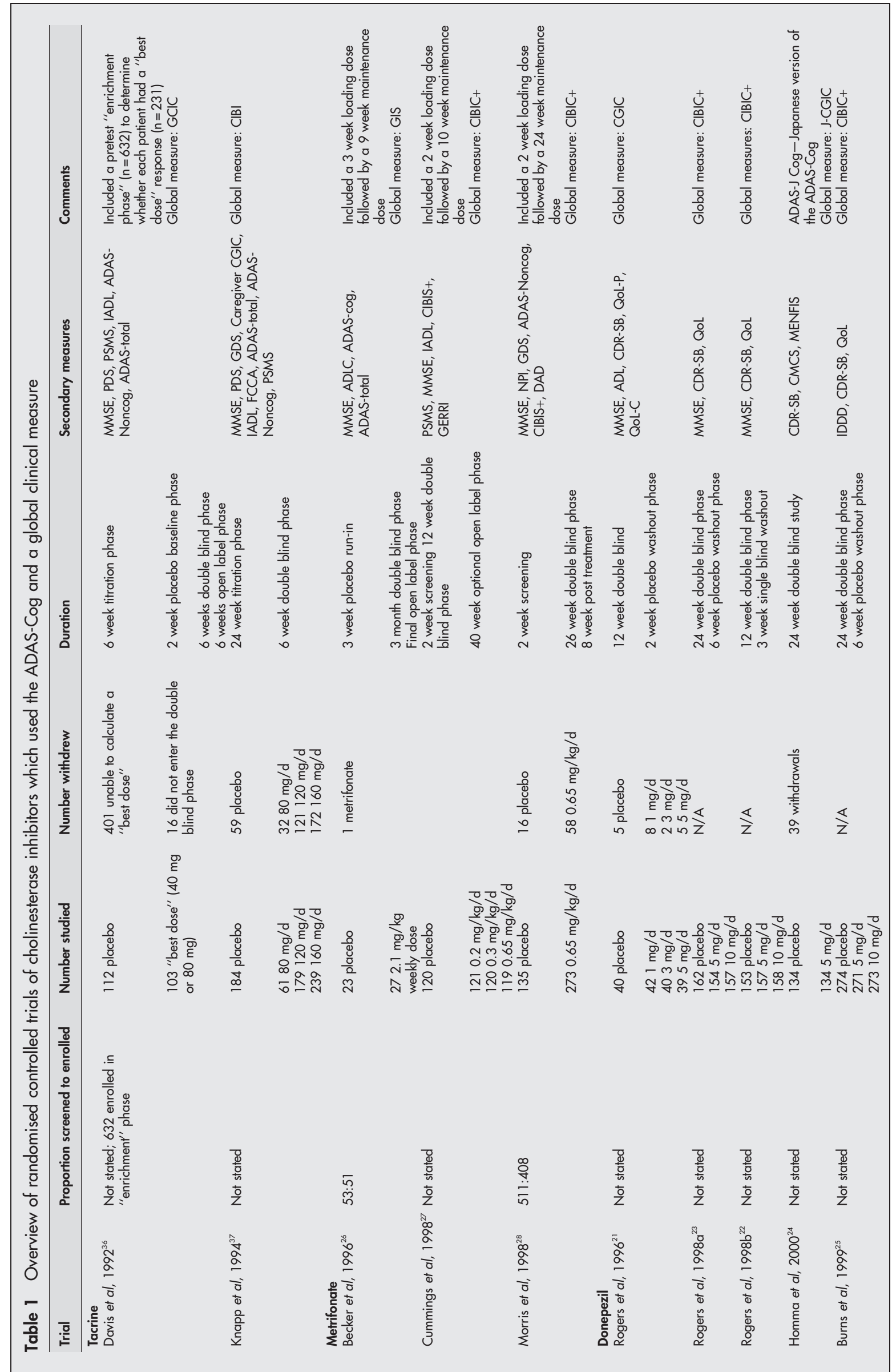




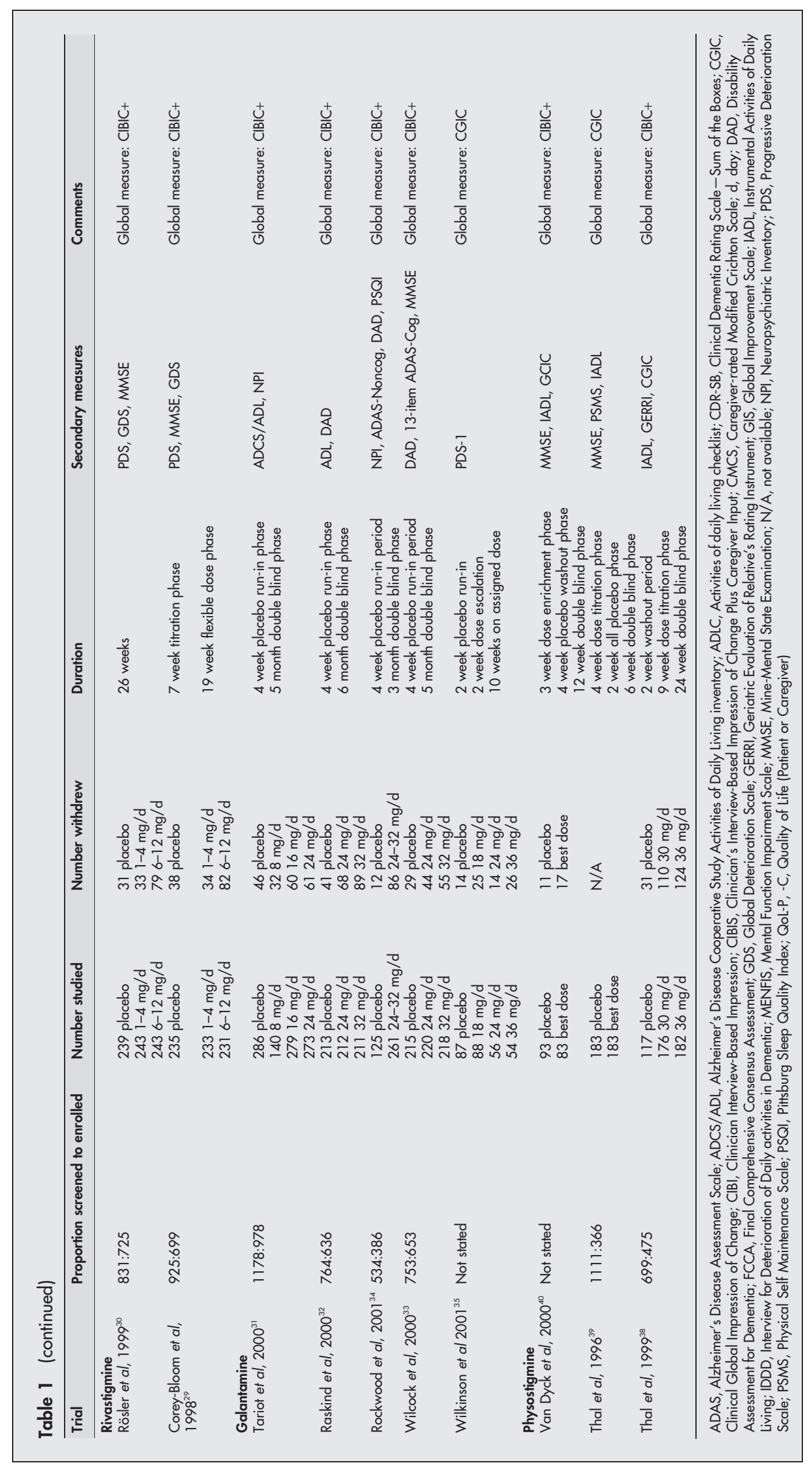



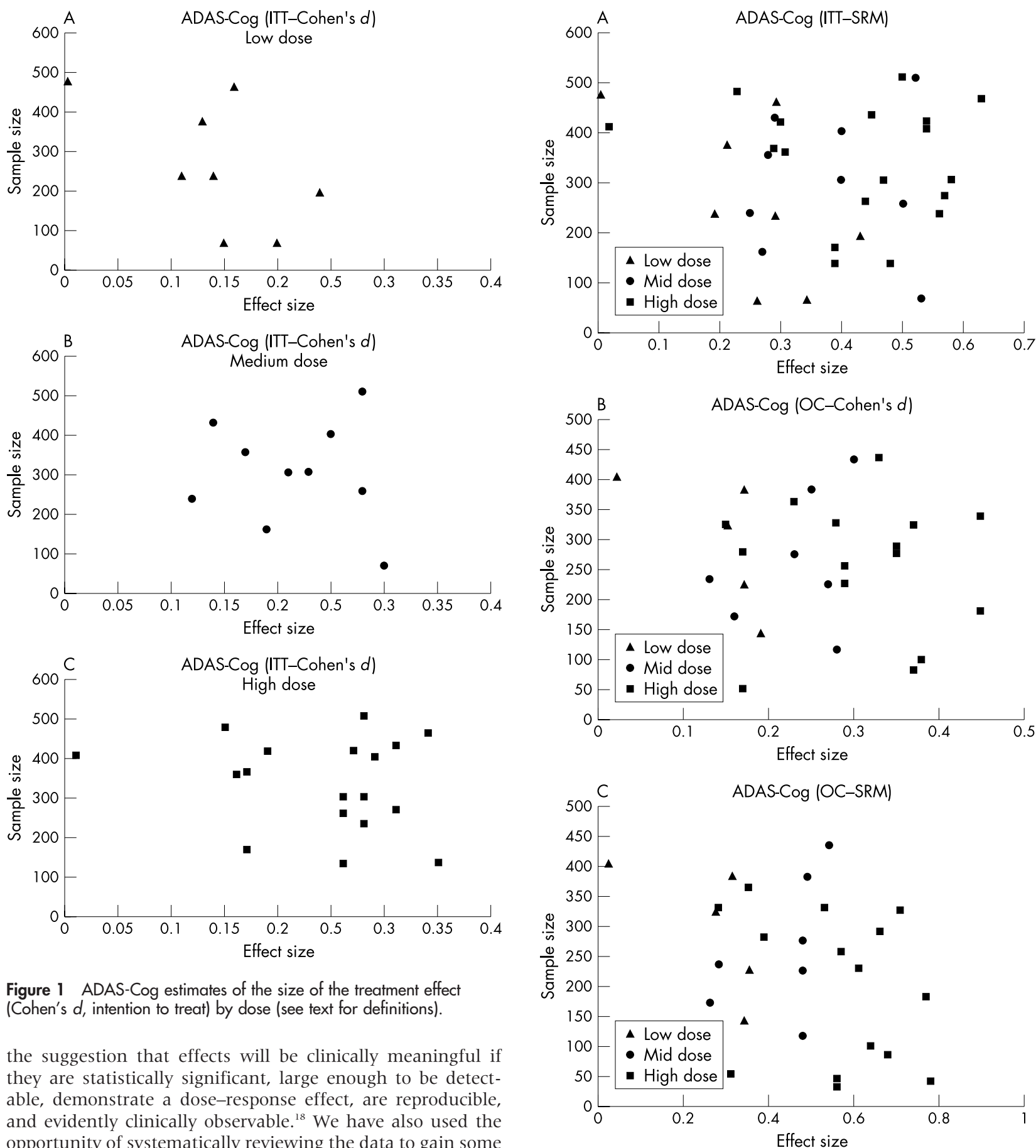

Figure 1 ADAS-Cog estimates of the size of the treatment effect (Cohen's $d$, intention to treat) by dose (see text for definitions).

the suggestion that effects will be clinically meaningful if they are statistically significant, large enough to be detectable, demonstrate a dose-response effect, are reproducible, and evidently clinically observable. ${ }^{18}$ We have also used the opportunity of systematically reviewing the data to gain some insight into the impact of LOCF analyses by comparing the effect sizes of ITT/LOCF with observed case analyses.

\section{METHODS}

\section{Search strategy}

For the selection of published trials the search strategy of the Canadian Coordinating Office for Health Technology Assessment (CCOHTA) was followed. ${ }^{6}$ Briefly, the CCOHTA selected trials by standard methodological criteria, which were then subjected to a blinded quality assessment using the Jadad Scale. ${ }^{19}$ Only those with a quality score of 5 or more were accepted. To maximise comparability, only those ChEI trials that used the ADAS-Cog and a separate global clinical measure were included, and these were restricted to trials with community dwelling patients with mild moderate AD. Qizilbash has urged caution in meta-analyses in dementia. ${ }^{20}$

Figure 2 Other ADAS-Cog estimates of the size of the treatment effect by type of effect size, and type of analysis, by low, mid (medium), and high doses.

Rather than a meta-analyses, a narrative review was undertaken with attention to trial selection, comparability and method of analysis, and with pre-specified criteria of the assessment of clinical meaningfulness.

Herein are summarised data for five trials of donepezil, ${ }^{21-25}$ three of metrifonate $e^{26-28}$ and two of rivastigmine. ${ }^{29} 30$ Since the CCOHTA review was published, five additional trials of galantamine have become available and have been included. ${ }^{31-35}$ We have also included the two tacrine trials that met all criteria ${ }^{36}{ }^{37}$ as did three trials of physostigmine. ${ }^{38-40}$ 


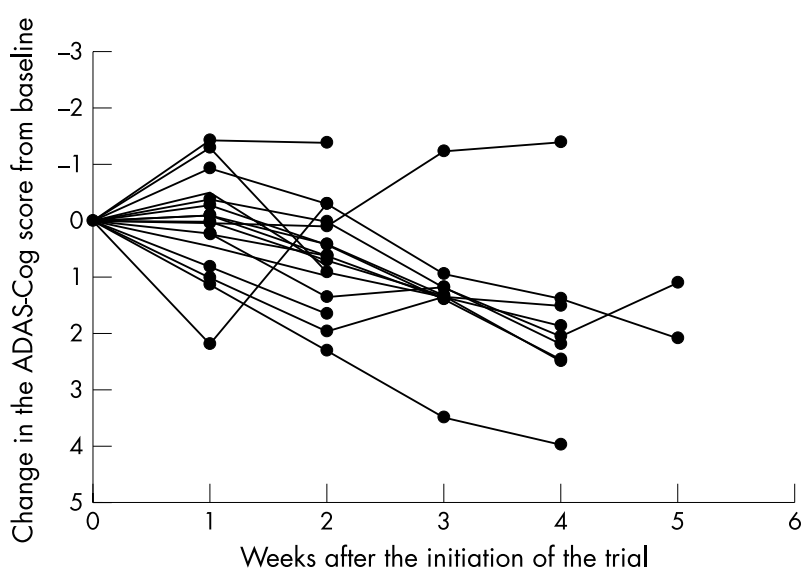

Figure 3 Inter-trial variability on ADAS-Cog placebo responses in Alzheimer's disease trials.

\section{Operationalisation of the criteria to assess meaningfulness}

Statistical significance was assessed through an overview of the published literature, and held to be the case whenever the primary analysis demonstrated that the results were unlikely $(p<0.05)$ to have been observed if the null hypothesis (of no difference between the active treatment and placebo groups) were true.

The criterion of being large enough to be clinically detectable was assessed by estimating effect sizes. Although the term is sometimes used simply to refer to the absolute differences between placebo and treatment groups, ${ }^{12}$ a standard effect size relates this number to the observed variance in the
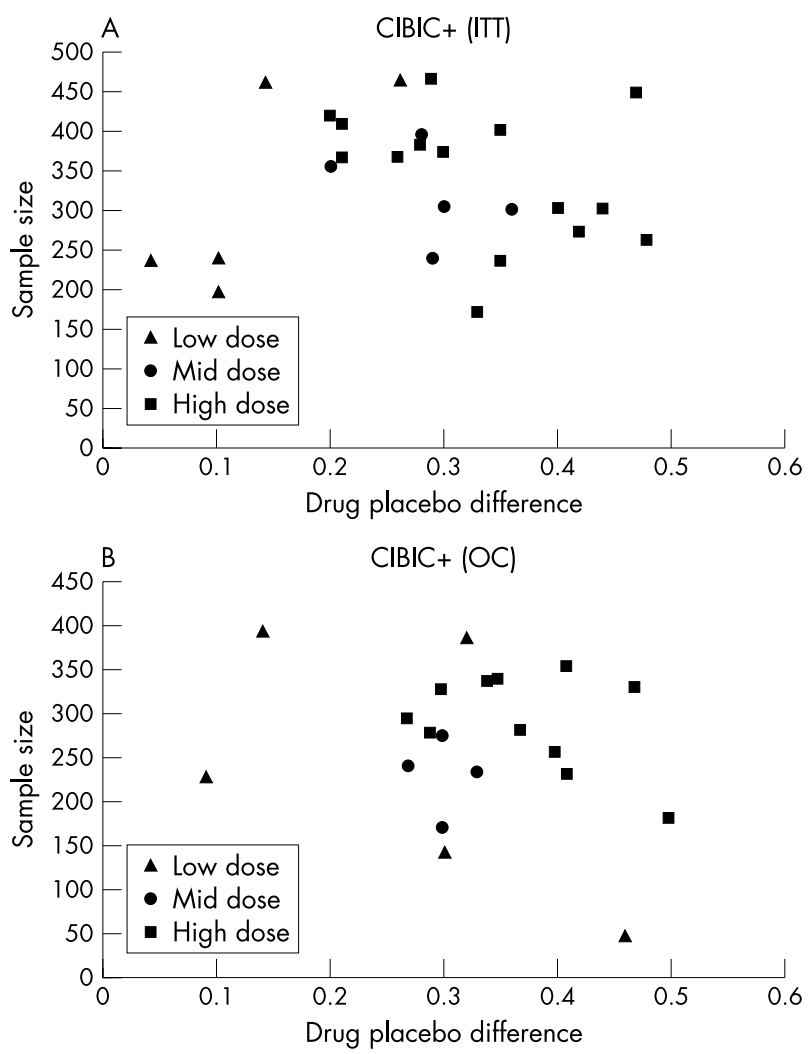

Figure 4 Size of the treatment difference in the CIBIC-PLUS raw score, by method of analysis. measures. ${ }^{41}$ Effect sizes were calculated as either (or both, where available) Cohen's $d$ or standardised response means (SRMs). Both Cohen's $d$ and SRMs calculate a "signal", for any measure, as the mean difference at the endpoint between those on active treatment and those on placebo, given baseline differences (that is, $x_{\mathrm{t} 2-\mathrm{t} 1}-\mathrm{y}_{\mathrm{t} 2-\mathrm{t} 1}$, where $x$ is the active treatment group, $y$ is the placebo group, $t_{2}$ is the endpoint and $t_{1}$ is the baseline). Both compare this signal in the average difference to an estimate of "noise": either the pooled baseline deviation (Cohen's $d$ ) or the pooled standard deviation of the change score (SRM). In the calculation of both Cohen's $d$ and SRM, and given that higher scores of each of the CIBIC-Plus and ADAS-Cog suggest worse disease, effect sizes that favour treatment will have negative values. Each study showed favourable effects, so that, for convenience only the absolute values are presented.

On theoretical grounds, and given that the best bias is conservative- that is, least likely to show a treatment benefit, the choice between Cohen's $d$ and SRM depends on assumptions about the characteristics of the sample under study. If the sample is artificially homogeneous at the outset (for example, as a result of strict inclusion/exclusion criteria) then the baseline variance will be artificially small, Cohen's $d$ will be speciously large, and thus SRM would be preferred. On the other hand, if the sample becomes more homogeneous over time (for example, through survivor effects) the opposite would be the case and Cohen's $d$ would be preferred. As this proposition has not been formally tested in antidementia trials, where possible, we present both estimates. Also presented are the absolute differences in relation to overall patterns of improvement or decline. We also estimated these measures with those observed to have completed the trial (observed cases; OC) and with the LOCF in an ITT analysis. Not every study precisely specifies the definition, but here the ITT sample is taken to comprise all patients who received at least one dose of double blind study medication, and for whom data are available from the baseline evaluation and at least one post-baseline assessment. An ITT/OC analysis includes only those patients who received at least one dose of study medication, had a baseline evaluation, and had a final evaluation at the scheduled end of the trial while on double blind study medication. This is also referred to as a "completers" analysis. An ITT/LOCF analysis consists of all patients who received at least one dose of study medication, and had at least one pretreatment evaluation and one evaluation after the start of treatment. The last observation is carried forward and used as a so-called endpoint evaluation.

Few published studies provide baseline standard deviation scores or standard deviations of the change scores, but these can be calculated from the sample size and standard errors of the mean treatment difference or confidence intervals. Whether these differences were large enough to be clinically detectable was considered on two grounds. Effect sizes greater than 0.20 are conventionally held to be clinically detectable. ${ }^{41}$ In addition, effect sizes for individual trials were correlated with scores on the global clinical measure used in the trial.

Where a dose-response relationship holds, the effect size will show peaks for each dose. In the case of most ChEIs, two doses were assessed: a low dose and a medium-high dose. Where each higher dose is reported separately, separate effect sizes are presented, giving small, medium and high dose effect size estimates. The doses were as follows: donepezil, no low dose, medium dose $5 \mathrm{mg}$ daily, high dose $10 \mathrm{mg}$ daily; rivastigmine, low dose $1.5 \mathrm{mg}$ twice daily, medium-high dose $3.0 \mathrm{mg}$ twice daily or higher; metrifonate, low dose $0.2 \mathrm{mg} / \mathrm{kg}$ bodyweight, medium dose $0.3 \mathrm{mg} / \mathrm{kg}$, high dose $0.65 \mathrm{mg} / \mathrm{kg}$; galantamine, low dose $4 \mathrm{mg}$ twice daily, medium dose $8 \mathrm{mg}$ 
twice daily, high dose $12 \mathrm{mg}$ twice daily or higher. Note that to achieve the highest dose, there is interval dose titration.

The demonstration of a dose response was tested by comparing effect sizes of a given drug across doses of that drug, and likewise between drugs. These data are presented as funnel plots. Funnel plots display the effect size against the sample size. ${ }^{42}$ They derive their name from the probability property that a sample estimate will more closely approximate the true value of the population parameter the larger the sample size, other things being equal. In consequence, the effect size will "funnel in" on the true value as the sample size increases.

Reproducibility was assessed first by examining the range of effect sizes between trials on the funnel plots. In addition, the distribution of the effect sizes across different ChEIs was observed. In each case, reproducibility was defined as comparability of the effects, considering variable sample size and trial duration, as portrayed in the funnel plots.

The criterion of being "evidently clinically observable" was operationalised as a statistically significant difference on the CIBIC-Plus or like global clinical measure. To summarise these measures, where no baseline variance is possible, and where change score variance terms are rarely presented, the effect size was calculated simply as the absolute difference in the proportions deteriorating, improving, or demonstrating no change. Their size and potential to show dose-response relationship can also be considered as measures of the reproducibility of the data.

\section{RESULTS}

Table 1 presents an overview of the dosing and size of each trial, the ratio of patients screened to those enrolled and the number of withdrawals from each arm of the trial. While withdrawals vary between the trials, there are more withdrawals in the treatment arms than in the placebo arms. Figure 1 presents a funnel plot of the effect sizes of ChEIs on the ADAS-Cog for the ITT/LOCF using Cohen's $d$, for the low, medium, and high doses (panels A-C, respectively). Statistical significance was obtained in each of the studies with an effect size of more than 0.15 and a sample size of more than $250(p<0.05)$. With four exceptions (from one study each of tacrine, rivastigmine, galantamine, and physostigmine) the high doses of each study showed effect sizes of greater than 0.20 using Cohen's $d$ and the LOCF/ITT analysis. In every case, the effect size was greater than 0.20 with the highest dose using the SRM. Figure 2 is the funnel plot for the ITT/LOCF using the SRM (panel A) and for the OC (panels B, C) analyses. Individual data points are plotted for each drug at each dose. In the ITT/LOCF analyses using Cohen's $d$ as the estimate of effect size, peaks are detectable at about 0.15 (panel A) and 0.25 , corresponding roughly to low and medium-high doses, respectively. The SRMs (fig 2, panel A) likewise show peaks, at about the median values of 0.26 (low dose) and 0.47 (high dose). As would be expected, the highest estimates are seen in the OC analyses (fig 2, panels B, C), with, for example, a median SRM in the OC medium-high dose studies being 0.56; (range 0.35 to 0.78 ).

Figure 3 provides some context for these estimates by noting the course of the ADAS-Cog changes in the placebo arms of the trials. With two exceptions, the trials show persistent declines in the placebo arms over time, although the rate of decline varies.

Figure 4 is a funnel plot of the effect sizes of ChEIs on the CIBIC-Plus for the ITT/LOCF (panel A) and OC (panel B) analyses. Individual data points are plotted for each drug at each dose. Again, two peaks are detectable, one about 0.15 and another about 0.25 , corresponding to low and mediumhigh doses, respectively. In general, the global clinical measures produced estimates of effect sizes (where these could be calculated) that were similar to the ADAS-Cog-for example, high dose ChEI, ITT/LOCF median SRM is 0.29 (range 0.20 to 0.47 ). The correlation of the ADAS-Cog effects sizes to the CIBIC+ effect sizes for ITT analyses was 0.29 for the ITT/LOCF analyses and 0.60 (SRM) for the OC analyses.

\section{DISCUSSION}

This study is part of a general strategy to assay the clinical importance of ChEIs. The studies reviewed suggest that antidementia drug trials show statistically significant differences that are large enough to be clinically detectable, demonstrate a dose response, are reproducible, and thus have evident clinical meaningfulness. ${ }^{18}$ Although controversy exists, ${ }^{43}$ ChEIs appear to have a biologically plausible basis. ${ }^{44}{ }^{45}$ In general, ChEIs produce clinically detectable effects on groups of patients treated for AD. The effects appear to be broadly reproducible, to demonstrate a dose response, and to be large enough to be clinically detectable.

These conclusions must be made with important caveats. Not all the data are available from all trials, as some employed different measures of cognition. Still, the ADASCog is now accepted as a standard, and decisions are being made about ChEIs on the basis of this measure, so it is useful to have some insight into its merit in drug trials. Another potential problem is publication bias. As far as can be determined, this report includes all known pivotal studies that employed the ADAS-Cog, for each of the three ChEIs widely used for $\mathrm{AD}$, but we note that there are no estimates with small sample sizes and small effect sizes, which is often a sign of publication bias. ${ }^{42}$

Another limitation is the generalisability of clinical trial data. Necessarily, the only patients considered in this overview are those who were eligible to take part in clinical trails. Given that dementia and multiple medical comorbidities are all strongly age related, ${ }^{46}$ many patients who suffer from dementia are not eligible for trials. In addition, many who meet an initial prescreen evaluation are excluded, so that only about $13 \%$ of patients referred for trials are enrolled. "Real world" effectiveness is therefore a challenge in interpreting clinical meaningfulness, ${ }^{6}$ although this is not limited to anti-dementia trials. ${ }^{47-50}$

The present analysis also helps provide some context for new studies. For example, data from two placebo controlled trials of donepezil have been published, which offer some insight into the size of the treatment effects for more than the maximum six months of the studies presented. Mohs et al studied 431 patients in a 54 week trial of donepezil versus placebo. ${ }^{51}$ The study did not use the ADAS-Cog or CIBIC-Plus, but rather employed a survival analysis of decline in one or more basic Activities of Daily Living. The Mini-Mental State Examination (MMSE) ( $^{52}$ was the main cognitive measure. Cohen's $d$ was 0.13 using the OC analysis, and 0.20 using the LOCF analysis. Winblad et al used the MMSE in a 52 week placebo controlled trial of donepezil..$^{53}$ We calculated Cohen's $d$ to be 0.42 using the OC analysis and 0.57 using the LOCF analysis. Thus estimates of long term effects vary between these trials, which have important design differences. Differences in drug effects also appear to exist between domains. For example, a meta-analysis of the impact of ChEIs on behaviour showed that while most produced statistically significant differences, effect sizes typically were less than $0.20 .^{54}$

Perhaps the most important caveat is that these group effects do not assist in the interpretation of a given effect in a given patient. The trials conducted for regulatory purposes are helpful in telling us that something is going on, but they do not tell us enough about what that is to provide much of a guide for individual patient decisions. This dilemma is perhaps best expressed by the dominance of the "no change" category on the CIBIC-Plus, which remains the single most 
common summary outcome of treatment. It is generally not the case that patients exhibit no clinically detectable change. Rather, it appears to be that these patients experience changes that the treating clinicians judge to be offsettingfor example, cognitive improvement but functional decline, or functional improvement but behavioural worsening. ${ }^{55} 56$ Perhaps buried in these summary scores are detectable patterns of change that may consist of reproducible effects of treatments. To mine these patterns, additional strategies are required..$^{58}$ Also, it appears that changes of a given magnitude in a measure such as the ADAS-Cog are variablethat is, a four point change indicating differing treatment effects depends on not just the severity of dementia, but also on the rate of disease progression. ${ }^{16}$

Still, analysis of effect sizes offers a means of understanding clinical meaningfulness by suggesting where it is likely to occur, and how likely it is to be evident to observers with varying degrees of expertise. It also allows comparison of the responsiveness (sensitivity to change) between measures within a given trial, ${ }^{59}$ and provides some insight into the effects of new drugs or new indications. For example, the six month data ${ }^{60}$ on the Ginkgo biloba extract EGb761 in the treatment of AD show effect sizes (Cohen's $d$ ) comparable to the effect sizes of cholinesterase inhibition (ADAS-Cog ITT 0.42 in OC analysis, and 0.33 with ITT/LOCF; Clinical Global Impression of Change (CGIC) 0.29 with OC analysis and 0.18 with ITT). In contrast, the 12 month data ${ }^{61}$ show an effect size of 0.20 with the ADAS-Cog, and 0 with the CGIC. Similarly, in a six month study in moderate to severe AD, patients on donepezil showed a small degree of improvement on the CIBIC-Plus, compared with continued decline in the placebo control group, resulting in an effect size of 0.49 (ITT/ LOCF; the OC analysis was 0.37). ${ }^{62}$ The effect size (SRM) detected by the CIBIC-Plus in a memantine trial was 0.27 (the absolute difference was 0.3 ). ${ }^{63}$ In a placebo controlled study of donepezil in vascular dementia, the effect sizes demonstrated by the ADAS-Cog ranged between 0.30 and 0.37 , depending on the dose $(5 \mathrm{mg}$ or $10 \mathrm{mg}$ ) or whether the LOCF or endpoint analysis was used. ${ }^{64}$ These estimates were similar to those seen in another trial using galantamine, in which the six month treatment effect size estimated by the ADAS-Cog was $0.35 .^{65}$

The effect size method thus allows for some quantification, and takes into account response in the placebo group, as does the estimate of the "number needed to treat" ${ }^{\prime 66}$ which also can be seen as a variant of an effect size calculation for proportions. ${ }^{42}$ These methods thus seem to be superior to estimation of the "minimal clinically important difference" which estimates signal better than noise, and which does not readily capture large placebo related changes. ${ }^{67}$

As noted, anti-dementia trials face the particular challenge of likely deterioration with or without treatment, and thus the problem of dropout bias, especially when early discontinuation is due to side effects related to medication. If patients exposed to drugs withdraw due to side effects, the effectiveness of the drug would be overestimated by an analysis which did not take dropout into account. In general, the remedy for this is an ITT analysis, employing either of two methods to handle missing data. In the ITT-non-completer equals failure method any patient whose data are missing is considered a treatment failure. Perhaps it was the experience of toxicity with the early ChEIs that persuaded the Cochrane Collaboration reviewers of ChEIs to be sceptical about the otherwise supposed, conservative bias (with respect to placebo effects) of an ITT/LOCF analyses. Although, in theory, early withdrawal can serve either to give a smaller or a larger effect than would have been the case had patients stayed in the trial, the present overview showed the ITT/LOCF analyses to be more conservative than the ITT/OC case analyses. A preferred method is the retrieved dropout analyses, in which patient measures are taken at the scheduled endpoint of the trial, whether they stayed in the study or not. This is not yet the standard for anti-dementia trials.

This study also helps contribute to our understanding of how to interpret the CIBIC-Plus. Although for the grouped data the effect size estimates of the CIBIC-Plus and ADASCog overlapped, the correlations between them were only notional for the ITT/LOCF analyses $(\sim 0.30)$ but higher for the OC analyses $(0.60)$. This suggests both that each measure assays different aspects of the treatment effect, ${ }^{58}$ in keeping with the original rationale for the use of a global clinical measure, ${ }^{68} 69$ and that patients who successfully complete studies might have recognisable profiles. The latter is important as clinicians (and thus the CIBIC-Plus) appear to be better at capturing deterioration than at capturing improvement, ${ }^{70}$ especially if improvement in some domains is seen in the face of deterioration in others. ${ }^{55} 56$ Such considerations point to a larger and compelling problem, which is not well addressed by the current studies, of how we get to grips with the idea of treatment success in $A D$, even when that success falls short of cure. ${ }^{71}$ As argued elsewhere, one important step in getting to grips with how to evaluate this aspect of clinical meaningfulness would be to assay the preferences of patients with $\mathrm{AD}$, and the preferences of their caregivers. ${ }^{57} 5871$

Estimation of the achievement of patient and caregiver preferences in anti dementia trials might also allow a better means of comparing drug treatment effects with effects that arise from non-pharmacological interventions. For example, in a meta-analysis of psychosocial interventions for caregivers of people with dementia, Brodaty and colleagues showed that such interventions yielded caregiver benefits of about 0.30 for any main outcome. ${ }^{72}$ Types of outcomes varied, being most successful in helping with the patient's mood, and least successful in helping with caregivers' feelings of burden. Comparing like outcomes with like is important if we are to adjudicate the concern that drug treatment for dementia is claiming more than its fair share if resources. ${ }^{73}$

In short, with reasonable consistency, ChEIs produce small-moderate effect sizes in clinical trials. A dose response can be demonstrated, and the patterns appear to be replicable both within and across trials. Dropout bias remains a concern in understanding group differences. Better descriptions of the patterns of treatment response are needed if we are to be guided in individual patient decisions about the effectiveness of treatment.

\section{ACKNOWLEDGEMENTS}

The author is grateful to Heather Merry, MSc, for her assistance in preparing the funnel plots and in calculating effect sizes from the published data.

$\mathrm{KR}$ is supported by an Investigator award from the Canadian Institutes of Health Research and by the Dalhousie Medical Research Foundation as the Kathryn Allen Weldon Professor of Alzheimer Research.

Competing interests: The author has conducted trials and/or received research and/or consulting and/or special fees from each of the following companies whose products are included in the review: Bayer; Janssen-Ortho; Novartis; Pfizer.

\section{REFERENCES}

1 Birks JS, Melzer D, Beppu H. Donepezil for mild and moderate Alzheimer's disease. Cochrane Database Syst Rev 2000;(4):CD001190.

2 Birks J, Grimley E, Lakovidou V, et al. Rivastigmine for Alzheimer's disease (Cochrane Review). In: Cochrane Library, Issue 2. Oxford: Update Software, 2001.

3 Bentham P, Gray R, Hills R, et al. Twelve-week response to cholinesterase inhibitors does not predict future benefit: the AD2000 experience [abstract]. Neurobiol Aging 2002;(suppl 1):337. 
4 Olin J, Schneider L. Galantamine for Alzheimer's disease. Cochrane Database Syst Rev 2002;(3):CD001747.

5 Clegg A, Bryant J, Nicholson T, et al. Clinical and cost-effectiveness of donepezil, rivastigmine, and galantamine for Alzheimer's disease. A systematic review. Int J Technol Assess Health Care 2002;18:497-507.

6 Husereau D, Wolfson C, Shukla VK. Drug treatments for Alzheimer's disease: efficacy, outcome measurements and cost-effectiveness. Technology Overview no 4. Canadian Coordinating Office for Health Technology Assessment, 2001.

7 Frisoni GB. Treatment of Alzheimer's disease with acetylcholinesterase inhibitors: bridging the gap between evidence and practice. J Neurol 2001;248:551-7.

8 Treves TA, Verchovsky R, Klimovitsky S, et al. Recruitment rate to drug trials for dementia of the Alzheimer type. Alzheimer Dis Assoc Disord 2000;14:209-11.

9 Qizilbash N, Whitehead A, Higgins J, et al. Cholinesterase inhibition for Alzheimer disease: a meta-analysis of the tacrine trials. Dementia Trialists' Collaboration. JAMA 1998;280:1777-82.

10 Pryse-Phillips W. Do we have drugs for dementia? Arch Neurol 1999;56:735-7.

11 Mayeux R, Sano M. Treatment of Alzheimer's disease. N Engl J Med 1999;341:1670-9.

12 McLendon BM, Doraiswamy PM. Defining meaningful change in Alzheimer's disease trials: the donepezil experience. J Geriatr Psychiatry Neurol $1999 ; 12: 39-48$.

13 Hills R, Gray R, Stowe R. Drop-out bias undermines findings of improved functionality with cholinesterase inhibitors [abstract]. Neurobiol Aging 2002;23(suppl 1):338

14 Jacobs D, Sano M, Marder K, et al. Age at onset of Alzheimer's disease: relation to pattern of cognitive dysfunction and rate of decline. Neurology 1994:44:1215-20.

15 Mitnitski A, Graham JE, Mogilner AJ, et al. The rate of decline in function in Alzheimer's disease and other dementias. J Gerontol Med Sci 1999;54:M65-M69

16 Farlow MR, Hake A, Messina J, et al. Response of patients with Alzheimer disease to rivastigmine treatment is predicted by the rate of disease progression. Arch Neurol 2001;58:417-22.

17 Rosen WG, Mohs RC, Davis KL. A new rating scale for Alzheimer's disease. Am J Psychiatr 1984;141:1356-64.

18 Rockwood K, MacKnight C. Assessing the clinical importance of statistically significant improvement in anti-dementia drug trials. Neuroepidemiology $2001 ; 20: 51-6$

19 Oremus M, Wolfson C, Perrault A, et al. Interrater reliability of the modified Jadad quality scale for systematic reviews of Alzheimer's disease drug trials. Dement Geriatr Cogn Disord 2001;12:232-6.

20 Qizilbash N. Systematic reviews. In: Qizilbash N, Schneider LS, Chui H, eds. Evidence-based Dementia Practice. Oxford: Blackwell Publishing, 2002.

21 Rogers SL, Friedhoff LT, the Donepezil Study Group. The efficacy and safety of donepezil in patients with Alzheimer's disease: results of a US multicentre, randomized, double-blind, placebo-controlled trial. Dementia 1996;7:293-303

22 Rogers SL, Doody RS, Mohs RC, et al. Donepezil improves cognition and global function in Alzheimer disease. Arch Intern Med 1998;158:1021-31.

23 Rogers SL, Farlow MR, Doody RS, et al. A 24-week, double-blind, placebocontrolled trial of donepezil in patients with Alzheimer's disease. Neurology 1998;50:136-45

24 Homma A, Takeda M, Imai Y, et al. Clinical efficacy and safety of donepezil on cognitive and global function in patients with Alzheimer's disease. Dement Geriatr Cogn Disord 2000;1 1:299-313.

25 Burns A, Rossor M, Hecker J, et al. The effects of donepezil in Alzheimer's Disease-results from a multinational trial. Dement Geriatr Cogn Disord 1999; 10:237-44.

26 Becker RE, Colliver JA, Markwell SJ, et al. Double-blind, placebo-controlled study of metrifonate, an acetylcholinesterase inhibitor, for Alzheimer disease. Alzheimer Dis Assoc Disord 1996;10:124-31.

27 Cummings JL, Cyrus PA, Bieber F, et al. Metrifonate treatment of the cognitive deficits of Alzheimer's disease. Metrifonate Study Group. Neurology 1998;50:1214-21.

28 Morris JC, Cyrus PA, Orazem J, et al. Metrifonate benefits cognitive, behavioral, and global function in patients with Alzheimer's disease. Neurology 1998;50:1222-30.

29 Corey-Bloom J, Anand R, Veach J, for the ENA 713 B352 Study Group. A randomized trial evaluating the efficacy and safety of ENA 713 (rivastigmine tartrate), a new acetylcholinesterase inhibitor, in patients with mild to moderately severe Alzheimer's disease. Int J Geriatr Psychopharmacol 1998;1:55-65.

30 Rösler M, Anand R, Cicin-Sain A, et al. Efficacy and safety of rivastigmine in patients with Alzheimer's disease: international randomised controlled trial. BMJ 1999;318:633-8.

31 Tariot PN, Solomon PR, Morris JC, et al. A 5-month, randomized, placebocontrolled trial of galantamine in AD. Neurology 2000;54:2269-76.

32 Raskind MA, Peskind ER, Wessel T, et al. A 5-month, randomized, placebocontrolled trial of galantamine in AD. The Galantamine USA-10 Study Group. Neurology 2000;54:2269-76.

33 Wilcock GK, Lilienfeld S, Gaens E, on behalf of the Galantamine International1 Study Group. Efficacy and safety of galantamine in patients with mild to moderate Alzheimer's disease: multicentre randomised controlled trial. BMJ 2000;321:1-7

34 Rockwood K, Mintzer J, Truyen L, et al. Effects of a flexible galantamine dose in Alzheimer's disease: a randomised, controlled trial. J Neurol Neurosurg Psychiatry 2001;71:589-95.
35 Wilkinson D, Murray J. Galantamine: a randomized, double-blind, dose comparison in patients with Alzheimer's disease. Int J Geriatr Psychiatry $2001 ; 16: 852-7$

36 Davis KL, Thal U, Gamzu ER, et al. A double-blind, placebo-controlled multicenter study of tacrine for Alzheimer's disease. N Engl J Med 1992;327:1253-9

37 Knapp MJ, Knopman DS, Solomon PR, et al. A 30-week randomized controlled trial of high-dose tacrine in patients with Alzheimer's disease. JAMA 1994;271:985-91.

38 Thal LJ, Ferguson JM, Mintzer J, et al. A 24-week randomized trial of controlled-release physostigmine in patients with Alzheimer's disease. Neurology 1999;52:1146-52.

39 Thal L, Schwartz G, Sano M, et al. A multicenter double-blind study of controlled-release physostigmine for the treatment of symptoms secondary to Alzheimer's disease. Physostigmine Study Group. Neurology 1996;47:1389-95.

40 Van Dyck $\mathrm{CH}$, Newhouse $\mathrm{P}$, Falk WE, et al. Extended-release physostigmine in Alzheimer disease: a multicenter, double-blind, 12-week study with dose enrichment. Physostigmine Study Group. Arch Gen Psychiatry 2000;57:157-64.

41 Cohen J. Statistical Power Analyses for the Behavioural Sciences, 2nd ed. Hillsdale, NJ: Lawrence Erlbaum Associates, 1988.

42 Light RJ, Pillimer DB. Summing Up: The science of reviewing research. Cambridge, MA: Harvard University Press, 1984.

43 Davis KL, Mohs RC, Marin D, et al. Cholinergic markers in elderly patients with early signs of Alzheimer disease. JAMA 1999;281:1401-6.

44 Francis PT, Palmer AM, Snape M, et al. The cholinergic hypothesis of Alzheimer's disease: a review of progress. J Neurol Neurosurg Psychiatry 1999;66:137-47.

45 DeKosky ST, Ikonomovic MD, Styren SD, et al. Upregulation of choline acetyltransferase activity in hippocampus and frontal cortex of elderly subjects with mild cognitive impairment. Ann Neurol 2002;51:145-55.

$46 \mathrm{McDowell}$ I. Alzheimer's disease: insights from epidemiology. Aging (Milano) 2001;13:143-62.

47 Bahit MC, Cannon CP, Antman EM, et al. Direct comparison of characteristics, treatment, and outcomes of patients enrolled versus patients not enrolled in a clinical trial at centers participating in the TIMI 9 Trial and TIMI 9 Registry. Am Heart J 2003; 145:109-17.

48 Sokka T, Pinkus T. Eligibility of patients in routine care for major clinical trials of anti-tumor necrosis factor alpha agents in rheumatoid arthritis. Arthritis Rheum 2003:48:313-18.

49 Licht RW. Limits of the applicability and generalizability of drug trials in mania. Bipolar Disord 2002;4(suppl 1):66-8.

50 Swanson GM, Bailiar JC III. Selection and description of cancer clinical trials participants - science or happenstance? Cancer 2002;95:950-9.

51 Mohs RC, Doody RS, Morris JC, et al. A 1-year, placebo-controlled preservation of function survival study of donepezil in AD patients. Neurology 2001;57:481-8

52 Folstein MF, Folstein S, McHugh PR. Mini-mental state. A practical method for grading the cognitive state of patients for the clinician. J Psychiatr Res 1975;12:189-98.

53 Winblad B, Engedal K, Soininen $\mathrm{H}$, et al. A 1-year, randomized, placebocontrolled study of donepezil in patients with mild to moderate AD. Neurology 2001;57:489-95.

54 Trinh NH, Hoblyn J, Mohanty S, et al. Efficacy of cholinesterase inhibitors in the treatment of neuropsychiatric symptoms and functional impairment in Alzheimer disease: a meta-analysis. JAMA 2003;289:210-16.

55 Joffres C, Bucks RS, Haworth J, et al. Patterns of clinically detectable treatment effects with galantamine: a qualitative analysis. Dement Geriatr Cogn Disord 2003; 15:26-33

56 Joffres C, Graham J, Rockwood K. Qualitative analysis of the clinician interview-based impression of change (Plus): methodological issues and implications for clinical research. Int Psychogeriatr 2000;12:403-13.

57 Rockwood K, Graham JE, Fay S. ACADIE Investigators. Goal setting and attainment in Alzheimer's disease patients treated with donepezil. J Neurol Neurosurg Psychiatry 2002;73:500-7.

58 Rockwood K, Joffres C. Halifax Consensus Conference on Understanding the Effects of Dementia Treatment. Improving clinical descriptions to understand the effects of dementia treatment: consensus recommendations. Int J Geriatr Psychiatry 2002;17:1006-11.

59 Rockwood K, P Stolee. Responsiveness of outcome measures in an antidementia drug trial. Alzheimer Dis Assoc Disord 2000;14:182-5.

60 Le Bars PL, Katz MM, Berman N, et al. A placebo-controlled, double-blind, randomized trial of an extract of Ginkgo biloba for dementia. North American EGb Study Group. JAMA 1997;278:1327-32.

61 LeBars PL, Kiesel M, Itil KZ. A 26-week analysis of a double-blind, placebocontrolled trial of the ginkgo biloba extract EGb 761 in dementia. Dement Geriatr Cogn Disord 2000;1 1:230-7.

62 Feldman H, Gauthier S, Hecker J, et al. A 24-week, randomized, doubleblind study of donepezil in moderate to severe Alzheimer's disease. Neurology 2001;57:613-20.

63 Reisberg B, Doody R, Stoffler A, et al. Memantine in moderate-to-severe Alzheimer's disease. N Engl J Med 2003;348:1333-41.

64 Wilkinson D, Doody R, Helme R, et al. Donepezil in vascular dementia: A randomized, placebo-controlled study. Neurology 2003;61:479-86.

65 Erkinjuntti T, Kurz A, Gauthier S, et al. Efficacy of galantamine in probable vascular dementia and Alzheimer's disease combined with cerebrovascular disease: a randomised trial. Lancet 2002;359:1283-90.

66 Livingstone G, Katona C. How useful are cholinesterase inhibitors in the treatment of Alzheimer's disease? A number needed to treat analysis. Int J Geriatr Psychiatry 2000;15:203-7. 
67 Burback D, Molnar FJ, St John P, et al. Key methodological features of randomized controlled trials of Alzheimer's disease therapy. Dement Geriatr Cogn Disord 1999;10:534-40.

68 Schneider LS, Olin JT, Doody RS, et al. Validity and reliability of the Alzheimer's Disease Cooperative Study-Clinical Global Impression of Change. Alzheimer Dis Assoc Disord 1997;11(suppl 2):S22-32.

69 Knopman DS, Knapp MJ, Gracon SI, et al. The Clinician Interview-Based Impression (CIBI): a clinician's global change rating scale in Alzheimer's disease. Neurology 1994:44:2315-21.
70 Quinn J, Moore M, Benson DF, et al. A videotaped CIBIC for dementia patients: validity and reliability in a simulated clinical trial. Neurology 2002;58:433-7.

71 Rockwood K, Wallack M, Tallis R. The treatment of Alzheimer's disease: understanding success short of cure. Lancet Neurol 2003;2:630-3.

72 Brodaty H, Green A, Koschera A. Meta-analysis of psychosocial interventions for caregivers of people with dementia. J Am Geriatr Soc 2003;51:657-64. 73 Heller T, Heller L. First among equals? Does drug treatment claim more than its fair share of resources? Dementia 2003;2:7-19.

\section{Clinical Evidence-Call for contributors}

Clinical Evidence is a regularly updated evidence based journal available worldwide both as a paper version and on the internet. Clinical Evidence needs to recruit a number of new contributors. Contributors are health care professionals or epidemiologists with experience in evidence based medicine and the ability to write in a concise and structured way.

\section{Currently, we are interested in finding contributors with an interest in}

the following clinical areas:

Altitude sickness; Autism; Basal cell carcinoma; Breast feeding; Carbon monoxide poisoning; Cervical cancer; Cystic fibrosis; Ectopic pregnancy; Grief/bereavement; Halitosis; Hodgkins disease; Infectious mononucleosis (glandular fever); Kidney stones; Malignant melanoma (metastatic); Mesothelioma; Myeloma; Ovarian cyst; Pancreatitis (acute); Pancreatitis (chronic); Polymyalgia rheumatica; Post-partum haemorrhage; Pulmonary embolism; Recurrent miscarriage; Repetitive strain injury; Scoliosis; Seasonal affective disorder; Squint; Systemic lupus erythematosus; Testicular cancer; Varicocele; Viral meningitis; Vitiligo However, we are always looking for others, so do not let this list discourage you.

\section{Being a contributor involves:}

- Appraising the results of literature searches (performed by our Information Specialists) to identify high quality evidence for inclusion in the journal.

- Writing to a highly structured template (about 2000-3000 words), using evidence from selected studies, within 6-8 weeks of receiving the literature search results.

- Working with Clinical Evidence Editors to ensure that the text meets rigorous epidemiological and style standards.

- Updating the text every eight months to incorporate new evidence.

- Expanding the topic to include new questions once every 12-18 months.

If you would like to become a contributor for Clinical Evidence or require more information about what this involves please send your contact details and a copy of your CV, clearly stating the clinical area you are interested in, to Claire Folkes (cfolkes@bmigroup.com).

\section{Call for peer reviewers}

Clinical Evidence also needs to recruit a number of new peer reviewers specifically with an interest in the clinical areas stated above, and also others related to general practice. Peer reviewers are health care professionals or epidemiologists with experience in evidence based medicine. As a peer reviewer you would be asked for your views on the clinical relevance, validity, and accessibility of specific topics within the journal, and their usefulness to the intended audience (international generalists and health care professionals, possibly with limited statistical knowledge). Topics are usually 2000-3000 words in length and we would ask you to review between 2-5 topics per year. The peer review process takes place throughout the year, and our turnaround time for each review is ideally 10-14 days.

If you are interested in becoming a peer reviewer for Clinical Evidence, please complete the peer review questionnaire at www.clinicalevidence.com or contact Claire Folkes(cfolkes@bmjgroup.com). 


\section{PostScript}

\section{CORRESPONDENCE}

\section{Evidence for an association between the CSF HVA:5-HIAA ratio and aggressiveness in frontotemporal dementia but not in Alzheimer's disease}

In their recent paper, Soderstrom et al confirmed their preliminary data suggesting that the CSF HVA:5-HIAA ratio was associated with psychopathic traits and, in particular, violent and aggressive behaviour with childhood onset and adult expression. These findings might indeed reflect changed dopaminergic activity, possibly as a result of serotonergic dysregulation. We hypothesise that their findings might be applicable to other brain disorders characterised by specific behavioural disturbances, including aggression and agitation. Indeed, since several studies have found associations between altered serotonergic neurotransmission and aggression in persons with dementia, ${ }^{23}$ we could propose that the CSF HVA:5-HIAA ratio might be associated with aggression in persons with dementia as well. To test this hypothesis, we performed an interim analysis on 102 out of 302 patients who were included in a prospective and longitudinal study on neurochemical and genetic correlates of behavioural and psychological signs and symptoms of dementia (BPSD). The data presented further support a general application of the interesting findings of Soderstrom et al. ${ }^{1}$

Patients with various neurodegenerative forms of dementia were included in this prospective study, and were followed up by means of a neuropsychological and behavioural assessment every six months. In any case of death, brain autopsy was performed for neurochemical analysis as well as for neuropathological confirmation of the clinical diagnosis. All subjects and their caregivers gave informed consent to participation in the study, which was approved by the local ethics committee.

At baseline, behaviour was assessed by means of a battery of behavioural assessment scales which included the Behavioural Pathology in Alzheimer's Disease Rating Scale (Behave-AD) and the Cohen-Mansfield Agitation Inventory (CMAI). Lumbar puncture was performed between 9 and 10 am following overnight bed rest and fasting. The first $11 \mathrm{ml}$ of CSF were collected in several polypropylene vials that were immediately frozen in liquid nitrogen and stored at $-80^{\circ} \mathrm{C}$. Neurochemical analysis was carried out on the CSF fraction containing 6-7.5 $\mathrm{ml}$ by means of high performance liquid chromatography and electrochemical detection according to a modification of a recently described method. ${ }^{4}$ Routine investigation of the CSF included cell count, total protein and glucose analysis, and agar gel electrophoresis of proteins

For this interim analysis, HVA and 5-HIIA levels were determined in the CSF of 13 participants with frontotemporal lobe dementia (FTD) and 89 participants with probable Alzheimer's disease (AD). Spearman Rank
Order was used for correlation analysis between the CSF HVA:5-HIAA ratio and BPSD, applying SigmaStat Software (SPSS Science, Erkrath, Germany).

In the $\mathrm{AD}$ patient group, no significant correlations were found between the CSF HVA:5-HIAA ratio and Behave-AD clusters, total and global scores, or CMAI clusters (aggressive, physically non-aggressive, and verbally agitated behaviours) and total scores. In persons with FTD, however, the CSF HVA:5-HIAA ratio correlated significantly with the Behave-AD aggressiveness cluster score $(r=0.586 ; \mathrm{p}=0.033)$ and with the CMAI verbally agitated behaviour cluster score $(r=0.564 ; \mathrm{p}=0.041)$. Despite small sample sizes, effects of treatments were ruled out by comparing the CSF levels of HVA $(t$ test: $\mathrm{p}=0.691), 5$-HIAA $(\mathrm{p}=0.370)$, and the CSF HVA:5-HIAA ratio $(\mathrm{p}=0.157)$ between six untreated subjects with FTD and seven subjects with FTD who were receiving atypical antipsychotics.

Our preliminary results revealed an association between aggression and the CSF HVA:5-HIAA ratio in participants with FTD but not in those with $\mathrm{AD}$. More refined neurochemical analyses, including the determination of all catecholamines and serotonin in an extended population of FTD patients, are scheduled. These will allow further testing of the hypothesis that altered serotonergic modulation of dopaminergic neurotransmission leads to BPSD and in particular to aggression. Meanwhile, our findings suggest that the association between the CSF HVA:5-HIAA ratio and aggression as observed by Soderstrom et al ${ }^{1}$ is not limited to violent and aggressive behaviour with childhood onset and adult expression, but may indicate an underlying pathophysiological mechanism that may be common to aggressive symptomatology in other brain disorders, such as frontotemporal lobe dementia.

S Engelborghs, E Vloeberghs, K Maertens, B Marescau, P P De Deyn

Laboratory of Neurochemistry and Behaviour, BornBunge Foundation, University of Antwerp, Belgium

S Engelborghs, P P De Deyn

Department of Neurology, Middelheim General Hospital, Antwerp, Belgium

Correspondence to: Professor P P De Deyn; peter.dedeyn@ua.ac.be

\section{References}

1 Soderstrom H, Blennow K, Sjodin A-K, et al. New evidence for an association between the CSF HVA:5-HIAA ratio and psychopathic traits. J Neurol Neurosurg Psychiatry 2003;74:918-21.

2 Lai MKP, Tsang SWY, Francis PT, et al. Reduced $5-\mathrm{HT}_{1 \mathrm{~A}}$ receptor binding in the temporal cortex correlates with aggressive behavior in Alzheimer disease. Brain Res 2003;974:82-7.

3 Sukonick DL, Pollock BG, Sweet RA, et al. The 5 -HTTPR*S/*L polymorphism and aggressive behavior in Alzheimer disease. Arch Neurol 2001;58:1425-8.

4 Engelborghs S, Marescau B, De Deyn PP. Amino acids and biogenic amines in cerebrospinal fluid of patients with Parkinson's disease. Neurochem Res 2003;28:1145-50

\section{Extensive radiculopathy: another false localising sign in intracranial hypertension}

We read with interest the review by Larner on false localising signs. Among the various false localising signs described in patients with intracranial hypertension (ICHT), radiculopathy is an important manifestation which is probably under recognised. Many authors have documented subtle features of radiculopathy in patients with isolated intracranial hypertension (IIH). The usual manifestations of radiculopathy in these cases were acral paraesthesias, ${ }^{2}$ and backache and radicular pain. ${ }^{34}$ Rarely, motor deficits due to radiculopathy caused by ICHT have been described. ${ }^{56}$

Obeid et al reported two patients with extensive radiculopathy due to $\mathrm{ICHT}^{5}$; one individual had IIH and the other had cerebral sinus venous thrombosis. Both persons had papilloedema, marked visual impairment, and flaccid areflexic quadriparesis with normal MRI of brain, brainstem, and cervical spinal cord. The electrophysiological findings were consistent with radiculopathy. Both individuals initially received intravenous immunoglobulin for Guillain-Barré syndrome, without benefit, but they responded well to lumboperitoneal shunting. We also encountered two such cases with angiographically proven cerebral venous sinus thrombosis. ${ }^{6}$

The most likely mechanism at the basis of radiculopathy appears to be similar to that of other cranial neuropathies in ICHT-that is, mechanical compression of nerve roots, due to elevated CSF pressure distending the subarachnoid space. Documented enlargement of spinal subarachnoid space and distended root pouches in a patient with radicular pain and areflexia due to IIH supports this view. ${ }^{3}$ Radiculopathy secondary to ICHT has been reported almost exclusively in patients with IIH or cerebral venous sinus thrombosis.

Other causes of ICHT may not induce a diffuse increase in pressure in both intracranial and intraspinal compartments, and are unlikely to manifest as radiculopathy. The constellation of flaccid-areflexic quadriplegia and papilloedema may be misdiagnosed as Guillain-Barré syndrome with papilloedema. Careful analysis of the evolution of symptoms, estimation of CSF pressure, and appropriate vascular imaging should help to correctly identify the cause of ICHT.

A Moosa, M A Joy, A Kumar

Department of Neurology, Amrita Institute of Medical Sciences and Research Center, Cochin, Kerala, India

\section{Correspondence to: $\operatorname{Dr} \mathrm{N}$ V A Moosa;} ahsanmoosa@yahoo.com

\section{References}

1 Larner AJ. False localising signs. J Neuro Neurosurg Psychiatry 2003:74:415-18.

2 Round R, Keane JR. The minor symptoms of increased intracranial pressure: 101 patients with benign intracranial hypertension. Neurology 1988;38:1461-4.

3 Bortoluzzi M, Di Lauro L, Marini G. Benign intracranial hypertension with spinal and radicular pain. J Neurosurg 1982;57:833-6. 
4 Santinelli R, Tolone C, Toraldo R, et al. Familial idiopathic intracranial hypertension with spinal and radicular pain. Arch Neurol 1998;55:854-6.

5 Obeid T, Awada A, Mousali Y, et al. Extensive radiculopathy: a manifestation of intracranial hypertension. Eur I Neurol 2000;7:549-53.

6 Moosa A, Kishore A, Gupta AK, et al. Blindness, ophthalmoplegia and extensive radiculopathy-an unusual clinical syndrome in intracranial sinovenous thrombosis. Neurol India (in press).

\section{Role of entacapone in later Parkinson's disease not yet established}

The study by Brooks and Sagar, ${ }^{1}$ along with a number of previous others, demonstrates benefit for the catechol-O-methyltransferase (COMT) inhibitor entacapone when compared with placebo in Parkinson's disease (PD). However, this is insufficient evidence to justify the authors' conclusion that "it appears logical to employ levodopa combined with entacapone routinely". The important issue is not whether entacapone is more efficacious than placebo, but whether it is more or less clinically effective and cost effective than the other available treatments for patients with PD that is no longer adequately controlled by levodopa alone. Other available agents-including dopamine agonists and monoamine oxidase type $\mathrm{B}$ (MAOB) inhibitors-have also shown efficacy when compared with placebo. The paper would have benefited from a balanced discussion of the merits of entacapone compared with these other available treatment options.

Such a discussion is likely to have been inconclusive, however, as there is a dearth of reliable evidence on the best treatment for $\mathrm{PD}$, at any stage of the disease, since very few trials directly comparing active treatments have been undertaken. ${ }^{2}$ Companies are reluctant to undertake such trials, as it is not in their commercial interests to risk studies that might show their product to be inferior to that of a competitor. For this reason, independently funded trials-such as the current PD MED trial in the UK ${ }^{3}$ - should be supported to provide the reliable evidence on comparative efficacy needed to enable clinicians to make informed treatment decisions. Analysis, presentation and interpretation of the results of independent studies are also likely to be more objective than those of commercial studies. The potential for bias in commercial trials has recently been highlighted by systematic reviews and journal editorsfor example "systematic bias favours products which are made by the company funding the research" and "scientific studies can be manipulated in many ways to give results favourable to companies".

There are problems with the trial reported by Brooks and Sagar, and these are common to many PD trials, which are generally of poor methodological quality. ${ }^{2}$ In a progressive condition such as PD, it is important to evaluate the long term effects of treatment, and six months follow up is inadequate. The outcome measures used should reflect the impact of treatment on the patients' own perception of their functioning and quality of life, not that of clinicians as with the Unified Parkinson's Disease Rating Scale (UPDRS). It is unclear how well the data obtained from on-off diaries correlates with global quality of life. True intention to treat (ITT) analysis was not performed, since patients who withdrew from treatment were excluded from the analysis-ITT analysis requires such patients to be followed up and included in the analysis according to the arm to which they were allocated even if they have withdrawn from allocated therapy. ${ }^{6}$ Nearly 50\% more patients $(24.1 \% v 16.5 \%)$ dropped out of the entacapone arm than from the placebo arm and, in progressive diseases such as PD, dropout bias tends to favour the active treatment. ${ }^{7}$ Thus, although COMT inhibitors are welcome additions to the treatment options in PD, large, rigorously conducted comparative trials, assessing the long term impact on patient-rated measures of overall quality of life, are still needed to define their role in routine clinical practice.

K Wheatley, N Ives, R Gray University of Birmingham Clinical Trials Unit, University of Birmingham, Birmingham, UK

C Clarke

City Hospital, Birmingham, UK

Correspondence to: Professor K Wheatley, Birmingham Clinical Trials Unit, University of Birmingham, Park Grange, 1 Somerset Road, Edgbaston, Birmingham B15 2RR, UK ; k.wheatley@bham.ac.uk

Competing interests: We are investigators in the PD MED trial and thus have a vested interest in obtaining objective evidence on the best treatment for PD. CC has received honoraria for lectures, consultancy fees, and travel expenses from the manufacturers of many of the drugs discussed.

\section{References}

1 Brooks DJ, Sagar H, the UK-Irish Entacapone Study Group. Entacapone is beneficial in both fluctuating and non-fluctuating patients with Parkinson's disease: a randomised, placebo controlled, double blind six month study. J Neurol Neurosurg Psychiatry 2003;74:1071-9.

2 Wheatley K, Stowe RL, Clarke CE, et al. Evaluating drug treatments for Parkinson's disease: how good are the trials? BMJ 2002;324:1508-11.

3 PD MED: A phase III Parkinson's disease trial. www.pdmed.bham.ac.uk (accessed 17 March 2004).

4 Lexchin J, Bero LA, Diulbegovic B, et al. Pharmaceutical industry sponsorship and research outcome and quality: systematic review. BMJ 2003;326:1 167-70

5 Smith R. Medical journals and pharmaceutical companies: uneasy bedfellows. $B M$ 2003;326:1202-5.

6 Collins R, Peto R, Gray R, et al. Large-scale randomized evidence: trials and overviews. In: Weatherall D, Ledingham JGG, Warrell DA, eds. Oxford Textbook of Medicine, Volume 1. London: Oxford University Press, 1996:21-32.

7 Gray R, Stowe RL, Hills RK, et al. Non-random drop-out bias: intention to treat or intention to cheat? [Abstract] Control Clin Trials 2001;22:38S-39S

\section{Portal-systemic shunts, manganese, and parkinsonism}

I read with interest the article by Yoshikawa and colleagues. ${ }^{1}$ The authors reported the case of a 44 year old woman with hereditary haemorrhagic telangiectasia (Rendu-OslerWeber disease) involving the liver, who had raised serum concentrations of manganese, hyperintense areas in the basal ganglia on Tl weighted magnetic resonance images, and levodopa unresponsive parkinsonism. Naturally, I agree that the parkinsonism in this case is most probably related to portalsystemic (portal-venous) shunts. There are, however, two points that deserve clarification.
First, it is not entirely clear whether their fig 2 (left panel) shows portal-systemic or arteriovenous shunts. The authors say that the figure shows a selective angiogram of the superior mesenteric artery. If that were the case, there should not be a "feeding artery" involved in the intrahepatic shunts (as they state in the legend to fig 2). Instead, the figure would show the portal vein and portalsystemic shunts (that is, portal phase of the angiogram). If, on the other hand, the catheter were in the coeliac artery (as they mention in the text), then the figure would probably correspond to the arterial phase of the angiogram and show a feeding artery (the hepatic artery) and arteriovenous (not portalsystemic) shunts. Interestingly, there is evidence to suggest that both types of shunt may be necessary for the development of neurological complications in the presence of an intact (or mostly preserved) hepatic parenchyma. ${ }^{2}$ Thus excessive quantities of potentially toxic substances (for example, ammonia, manganese) passing directly from the gut to the systemic circulation through portal-systemic shunts could be rapidly cleared by a normal liver as long as the hepatic arterial blood flow is adequate.

Second, Yoshikawa and colleagues claim that the parkinsonism of their patient was induced by manganese. While this is a reasonable working hypothesis, the authors provide no direct evidence supporting such a statement. The fact that serum manganese was raised does not necessarily imply that manganese played a key role in the pathogenesis of parkinsonism. Indeed, their patient lacked various clinical features often seen in cases of manganese induced parkinsonism ${ }^{3}$ (for example, cock walk and propensity to fall backwards).

Levodopa unresponsive parkinsonism is a well known manifestation of chronic nonWilsonian hepatocerebral degeneration. ${ }^{4}$ Although blood concentrations of ammonia were within the normal range in the case reported by Yoshikawa and colleagues, the possibility of transient abnormal increases of ammonia occurring particularly after meals was not investigated.

$R$ de la Fuente-Fernández

Division of Neurology, Hospital A Marcide, Estrada San Pedro-Catabois s/n, 15405 Ferrol, A Coruña, Spain

Correspondence to: Dr Raúl de la Fuente-Fernández, rfuente@medynet.com

\section{References}

1 Yoshikawa K, Matsumoto M, Hamanaka M, et al. A case of manganese induced parkinsonism in hereditary haemorrhagic telangiectasia. J Neurol Neurosurg Psychiatry 2003;74:1312-14.

2 Yilmaz S, Kirimlioglu V, Katz D, et al. An attempt to decrease ammonia levels after portacaval anastomosis in dogs: hepatic periarterial neurectomy. Dig Dis Sci 2002;47:1943-52.

3 Calne DB, Chu NS, Huang CC, et al. Manganism and idiopathic parkinsonism: similarities and differences. Neurology 1994;44:1583-6.

4 Adams RD, Victor M, Ropper AH. Principles of neurology, 6th ed. New York: McGraw-Hill, 1997.

\section{Authors' reply}

We are pleased to have an opportunity to comment on the important issues raised by Dr de la Fuente-Fernández regarding a case of hereditary haemorrhagic telangiectasia 
with parkinsonism. Raised serum manganese combined with the abnormal findings in cranial magnetic resonance imaging and abdominal angiography were the rationale for our conclusion that the parkinsonism in our patient was induced by manganese that had accumulated because of portal-systemic shunting.

About the angiogram: the angiogram of the superior mesenteric artery presented in our manuscript showed a dilated feeding artery, a dense mottled hepatogram, and early filling of the hepatic vein. These findings concerned the arterial phase. The intrahepatic arteriovenous shunts were definite diagnostic evidence of hereditary haemorrhagic telangiectasia but not of portal-systemic shunts. We therefore agree with Dr de la FuenteFernández that we should have presented another angiogram in the portal phase showing a hypoplastic portal vein with abnormal vessels between the mesenteric and inferior vena cava to confirm the portal-systemic shunt.

About the parkinsonism: after the failure of treatment by levodopa, we took other measures to relieve the parkinsonism; for example, we persuaded the patient to avoid manganese-rich foods such as blueberries. Fortunately, her serum manganese gradually decreased below the normal upper limit during the next six months, and her neurological symptoms became less prominent. Alleviation of parkinsonism in inverse proportion to serum manganese concentrations suggests that the parkinsonism in this case may have been caused by manganese accumulation, and that the patient was in the early stage of manganese intoxication in which neurological symptoms were incomplete and partially reversible.

About transient hyperammonaemia: we searched for cases of hyperammonaemia related parkinsonism, and finally found a case with portal-systemic encephalopathy and parkinsonism which disappeared after treatment of the portal-systemic shunting. ${ }^{1}$ The mechanism of parkinsonism in that case is certainly open to debate, as hyperammonaemia is generally thought to cause disturbance of consciousness or negative myoclonus rather than parkinsonism. We do not deny the possibility that our patient may have had a transient increase in serum ammonia, though it seems unlikely when there had never been a disturbance of consciousness.

K Yoshikawa, M Nakagawa

Department of Neurology, Research Institute for Neurological Diseases and Geriatrics, Kyoto Prefectural University of Medicine, 465 Kawaramachi-

hirokoji, Kamigyo-ku, Kyoto 602-8566, Japan

Correspondence to: Dr K Yoshikawa kyoshika@koto.kpu-m.ac.jp

\section{Reference}

1 Federico P, Zochodne DW. Reversible parkinsonism and hyperammonaemia associated with portal vein thrombosis. Acta Neurol Scand 2001;103:198-200.

\section{Intraventricular assessment of preoperative electrographic recordings}

The paper by Song et al ${ }^{1}$ describes the placement of intraventricular arrays with endoscopic assistance for preoperative electrographic recordings for epilepsy surgery. The $4.2 \mathrm{~mm}$ external diameter rigid endoscope was introduced up to the temporal ostium from where the arrays were advanced until a point of resistance was felt.

In our paper ${ }^{2}$ we reported the use of a $1.2 \mathrm{~mm}$ outer diameter semirigid endoscope to explore the contents of the ventricles prior to electrode placement, with direct visual assessment of the final electrode position, which helped us obtain appropriate preresection electrographic recordings. Perhaps it would be more convenient to use semirigid endoscopes or slim fibrescopes to fully visualise the ventricle as well as flexible arrays to avoid electrode displacement resulting in unintentional cerebral lesions.

O H Jiménez

Dept Neurosurgery, Hospital General "Dr. Miguel Silva", Secretaría de, Salud de Michoacán, Mexico

N Nagore

Dept Neurosurgery, Universidad Michoacana de San Nicolás de Hidago, Morelia, Michóacán, CP 58000,

Correspondence to: $\operatorname{Dr} O$ Jimenez, ohjv@yahoo.com.mx

\section{References}

1 Song JK, Abou-Khalil B, Konrad PE. Intraventricular monitoring for temporal lobe epilepsy: report on technique and initial results in eight patients. J Neurol Neurosurg Psychiatry 2003;74:561-5.

2 Jiménez $\mathrm{O}$, Leal R, Nagore N. Minimally invasive electrodiagnostic monitoring in epilepsy surgery. Br J Neurosurg 2002;16:498-500.

\section{Parkinsonism and persistent vegetative state after head injury}

Matsuda et al recently reported three patients with a persistent vegetative state (PVS) after severe head injury who, after recovering from prolonged disturbance of consciousness, presented parkinsonian features (mainly rigidity and hypokinesia) which improved after levodopa treatment. ${ }^{1}$ MRI studies showed lesions in the dorsolateral midbrain and cerebral peduncles suggesting axonal injury involving the dopaminergic system (substantia nigra and ventral tegmental area). Similar observations were made in a series of 125 patients with severe vegetative state following head injury (survival time $1-10$ years). Nineteen of 49 patients surviving in fully developed or mild recovery stages of PVS initially presented with severe to moderate, mainly symmetrical, parkinsonian symptoms (amimia, rigidity, hypokinesia, convergence disorders). Following levodopa treatment, 11 patients showed incomplete and four full improvement of both the PVS and parkinsonism, while four patients showed complete recovery from both syndromes. However, in 15 patients-despite good recovery from the initial PVS and other neurological symptoms (spasticity, frontal and cerebellar symptoms), and long term levodopa treatment-a progressive parkinsonian syndrome (rigidity, hypokinesia) developed; in six patients this was associated with unilateral or bilateral resting tremor. In MRI studies done in 34 patients, 32 showed unilateral or bilateral lesions in the midbrain involving both the dorsolateral tegmentum and the cerebral peduncles. ${ }^{2}$

Neuropathological studies were undertaken in 32 patients surviving without essential improvement of the PVS for at least two months after head injury. Parkinsonian syndromes were severe in seven, moderate in five, and mild in four. ${ }^{3}$ In addition to older haemorrhages or necroses in the striatum $(n=6)$, globus pallidus and thalamus $(n=8)$, all brains revealed multiple lesions in the rostral brain stem with unilateral or bilateral focal lesions in the substantia nigra, vascular lesions in the lateral and dorsolateral midbrain in seven, and symmetrical postanoxic cellular depletion and gliosis or unilateral necroses in the substantia nigra in one case each. In nine cases, there was a good correlation between the severity of clinical parkinsonian signs and the severity and extent of nigral lesions; three patients showed severe parkinsonian signs associated with only mild nigral damage, but there was severe bilateral damage to the globus pallidus in two. In four patients the expression of clinical parkinsonian signs was more severe than the anatomical lesions, in particular the damage to the substantia nigra. The distribution pattern of the brain stem lesions correlated with the sequelae of transtentorhinal shifting caused by increased intracranial pressure; direct or "primary" traumatic lesions to the oral brain stem usually cause acute death, as seen in two young men with rupture of the diencephalon and acute haemorrhage into the substantia nigra or midbrain following severe and acute fatal head injuries. However, in rare patients with long survival following head injury, symmetrical necrosis of the substantia nigra without a clinical parkinsonian syndrome has been reported. ${ }^{4}$

The clinical phenotype of post-traumatic parkinsonism often resembles that in postencephalitic parkinsonism, both showing akinesia, rigidity, hypomimia, rare tremor, and optomotor and vegetative disorders. Both the lesion pattern and the therapeutic efficacy of long term levodopa treatment suggest a dysfunction of the striato-nigral dopaminergic system which, however, may show progressive decompensation in some patients with long lasting PVS after severe head injury.

$\mathrm{K} A$ Jellinger Institute of Clinical Neurobiology, Kenyongasse 18, A-1070 Vienna, Austria

Correspondence to: Dr Kurt A Jellinger, kurt.jellinger@univie.ac.at

\section{REFERENCES}

1 Matsuda W, Matsumura A, Komatsu $Y$, et al. Awakenings from persistent vegetative state: report of three cases with parkinsonism and brain stem lesions on MRI. J Neurol Neurosurg Psychiatry 2003;74:1571-3.

2 Kothbauer P, Gerstenbrand G, Jellinger K. Concerning the question of posttraumatic parkinsonian syndromes. Meeting of the Austrian Parkinsonian Society, Vienna, 1977. RocheFortbildungs-Service, 1977:1-6.

3 Jellinger K, Seitelberger F. Protracted posttraumatic encephalopathy. Pathology, pathogenesis, and clinical implications. J Neurol Sci 1970;104:51-94.

4 Huhn B, Jakob H. Traumatic brain stem lesions with long-term survival. Contribution to the pathology of substantia nigra and the pontine syndrome. Nervenarzt 1970;41:326-34.

\section{Authors' reply}

We greatly appreciate the thoughtful comments offered by Dr Jellinger, and his interest in our report of three cases in a persistent vegetative state (PVS) after severe head 
injury, who recovered from a prolonged disturbance of consciousness after they were given levodopa. ${ }^{1}$

Jellinger et al reports that in cases of prolonged post-traumatic coma the brains showed multiple lesions of primary and secondary traumatic origin and that the highest incidence of lesions was found in the rostral brain stem. These were considered to be almost exclusively of secondary origin, resulting from cerebral and peripheral circulatory disorders, post-traumatic oedema, and increased intracranial pressure. Primary (direct) traumatic lesions to the rostral brain stem usually cause acute death. ${ }^{2}$ In contrast to this report, the brain stem injuries in our cases suggested by MRI may have been the primary traumatic lesions. All these cases showed high intensity lesions in the dorsolateral midbrain on T2 weighted MRI. ${ }^{1}$ These findings implied that the midbrain was injured by tentorial compression induced by translatory and rotatory acceleration when the cranium was struck in its sagittal axis, or by posterolateral damage. MRI findings, particularly in the acute stage, are useful for evaluating primary brain damage. ${ }^{34}$ Furthermore, another distinctive feature of our cases was that the anatomical distribution of the lesions was not multifocal but was localised in the cerebral peduncle or the dorsolateral midbrain, implying diffuse axonal injury involving the substantia nigra or the ventral tegmental area. ${ }^{1}$ The neuroradiological findings, the clinical features of extrapyramidal dysfunction, and the efficacy of levodopa treatment all strongly suggest that the dopaminergic pathways were selectively damaged and caused defects in the nigrostriatal, mesocortical, or mesolimbic system.

As Dr Jellinger indicates, progressive decompensation in levodopa treatment is a considerable problem. However, not all our patients have required permanent medication; an example is case 1 in our report, whose recovery was sustained even after the levodopa treatment was discontinued. Some patients may need levodopa only as a trigger agent at the start of treatment to interrupt the vicious cycle of exhaustion of neurotransmitter. However, discriminating which cases fall into this category is very difficult and withdrawal of medication involves ethical problems.

In recent neuropathological and neuroradiological studies on PVS after traumatic brain injury, ${ }^{4-6}$ the most common structural abnormalities were diffuse axonal injury involving the corpus callosum, the dorsolateral aspect of the rostral brain stem, ${ }^{5}$ and the thalamus. ${ }^{6}$ Although the clinical features will vary in such cases, a take-home message which we learned from our three cases is that in any group of patients with PVS after severe head injury there may be some whose dopaminergic systems may have been selectively damaged; such individuals may respond to levodopa treatment. It is necessary to accumulate a great deal more clinical experience and data to elucidate the pathogenesis and pathophysiological mechanism of posttraumatic PVS. We respect Dr Jellinger's careful observations and descriptions of his cases of prolonged post-traumatic coma, and look forward to further views from him on this topic.

W Matsuda, Y Komatsu Department of Neurosurgery, Tsukuba Medical Centre Hospital, 1-3-1 Amakubo, Tsukuba, lbaraki 3050005, Japan
A Matsumura, K Yanaka Department of Neurosurgery, Institute of Clinical Medicine, University of Tsukuba, 1-1-1 Tennodai, Tsukuba, Ibaraki 305-8575, Japan

Correspondence to: Dr Wakoto Matsuda, wako@mua.biglobe.ne.jp

\section{References}

1 Matsuda W, Matsumura A, Komatsu Y, et al. Awakenings from persistent vegetative state: report of three cases with parkinsonism and brain stem lesions on MRI. J Neurol Neurosurg Psychiatry 2003;74:1571-3.

2 Jellinger K, Seitelberger F. Protracted posttraumatic encephalopathy. Pathology, pathogenesis, and clinical implications. I Neurol Sci 1970;104:51-94.

3 Matsumura A, Mitsui I, Ayuzawa S, et al. Prediction of reversibility of the brain stem dysfunction in head injury patients. In: Nakamura N, ed. Recent advances in neurotraumatology. Tokyo: Springer-Verlag, 1993:192-5.

4 Matsumura A, Meguro K, Shibata Y, et al. Persistent vegetative state [letter]. J Neurosurg 1998:89:895-6.

5 Kampfl A, Franz G, Franz A, et al. The persistent vegetative state after closed head injury: clinical and magnetic resonance imaging findings in 42 patients. J Neurosurg 1998;88:809-16.

6 Adams JH, Graham DI, Jennett B. The neuropathology of the vegetative state after an acute brain insult. Brain 2000;123:1327-38.

\section{BOOK REVIEWS}

\section{Year book of neurology and neurosurgery 2003}

Edited by Scott R Gibbs and Ashok Verma. Published by Mosby, Philadelphia, 2003 , pp 337, £73.99 (hardback). ISBN 0-32302058-5

Every year, countless journals publish myriad neurology and neurosurgery papers. There is immense attraction in the notion of a single volume yearbook that selects and comments upon the best. So, how well does the Yearbook of neurology and neurosurgery succeed in informing about significant advances in knowledge outside my own subspecialty area for 2003? The editors draw their selection from a survey of 500 journals, with something from most of those with big impact. Thirty seven associate editors assisted by reviewing the various subspecialty areas; of these all except 11 come from North America, of whom 9 are neurosurgeons rather than neurologists, an intriguing imbalance.

Papers selected cover every conceivable subspecialty, and sometimes the inconceivable. New gene mutations abound, illuminating case histories are provided, we learn that the visual cortex is hyper-excitable in migraineurs, and about informed consent in neurosurgery, and we are treated to pictures of new cranial remodelling devices for treating craniosynostosis. To provide a critical review of such a diversity of subject matter would be an impossibility. All one can do is to congratulate the editors for highlighting a selection of topics that opens one's eyes to the dazzling diversity of our specialty. Nevertheless, you would not go to a yearbook for a comprehensive review of developments in a particular subspecialty. Therefore, this is essentially armchair reading, and none the less useful for that.
Each article is summarised in half a page or so under the headings introduction (or background), methods, results, and conclusion. This is followed by a brief editorial comment, often interesting and pithy. At least some of this signed editorial comment is derived verbatim, or with only minor paraphrasing, from editorial comment in the journal originally publishing the chosen paper. ${ }^{1}$ So whose opinion are you really reading in the yearbook?

Although interestingly informative outside one's subspecialty, one does need to ask whether the concept of a single volume yearbook isn't becoming submerged by the sheer volume of potentially eligible papers published each year. And, although this 2003 yearbook arrived on my desk in December 2003, it predominantly covers papers published in 2001, with some from early 2002, and an occasional hangover from 2000. So, it isn't that up to date. I guess libraries will buy it, partly out of habit. But for individuals, $£ 74$ is a steep price for neurological coffee table reading.

M Donaghy

\section{Reference}

1 Donaghy M. Assessing the risk of drug-induced neurological disorders: statins and neuropathy. Neurol 2002;58:1321-2.

\section{Catatonia: a clinician's guide to diagnosis and treatment}

Max Fink, Michael Alan Taylor. Cambridge: Cambridge University Press 2003, pp 210, $£ 50.00$ (hardback). ISBN 0-521-82226-2.

This nicely produced book reviews one of the historically most interesting, but clinically still very important, disorders of neuropsychiatry. Catatonia, described by Kahlbaum in the latter half of the 19th century, was hijacked by Kraepelin to be incorporated into his concept of dementia praecox, and almost disappeared from the literature in the first half of the 20th century, being finally eclipsed by the introduction of effective psychotropic drugs thereafter. But, as Fink and Taylor explore here, catatonia as a diagnosis is still a diagnostic challenge, with causes far beyond schizophrenia and a syndrome with effective treatment, notably, but not exclusively electroconvulsive therapy (ECT).

For those interested in the cerebral basis of psychiatry, a condition with the main presenting signs of mutism, immobility, negativism, posturing, stereotypy, and echophenomena cannot fail to attract attention, and the many faces of catatonia (title, chapter 3) are an olla podrida of neuropsychiatry. It is refreshing to find reference to Leonhard's work and the cycloid psychoses in a text from American authors, who are thoroughly appreciative of the European literature on their subject, and shyly critical of DSM-IV. Their overall conclusions are clear. Catatonia is a common stable syndrome, neuroleptic malignant syndrome is malignant catatonia, catatonia is not usually associated with schizophrenia, and it is a syndrome of motor dysregulation with a good prognosis-if identified and treated early. This book is a pleasure to read, but should be on the imperative reading list for all psychiatric trainees to inform them about the history of their discipline, the importance of neuropsychiatry, and how to write clearly.

M R Trimble 
New Oxford textbook of psychiatry, vols 1 and 2

M G Gelder, Jaun Lopez-lbor Jr, Nancy C Andreasen, eds. Oxford: Oxford University Press 2003, pp 2432, £125.00. ISBN 0-19852810-8

The New Oxford textbook is the latest and largest from the Oxford textbook of psychiatry's stable. The book was originally published in 2000 and has recently appeared in paperback. This is the best modern British textbook of psychiatry. It is over 2000 pages long and comes in two stout volumes. The international editorship is led by Michael Gelder, Emeritus Professor of Psychiatry at Oxford, with Spanish (Jaun Lopez-Ibor) and American (Nancy Andreasen) co-editors. The book is inevitably based on a myriad of individual contributions although the choice of contributor and standard of editing is exemplary.

The first volume covers general issues and the scientific basis of psychiatry, including a number of reviews of neurobiology. Interestingly, psychodynamic contributions have a separate section. The remainder of the first volume is taken up with coverage of the clinical syndromes of adult psychiatry, including substantial coverage of dementia.

The second volume includes review of special topics with a number of articles on aspects of the psychiatry and medical conditions. This includes a useful chapter on neurological disease by Maria Ron, and on epilepsy by Brian Toone. The remaining part of the second volume addresses the psychiatric subspecialties as well as having a substantial section on psychiatric treatments, both pharmacological and non-pharmacological.

This text is my personal first choice when I encounter a problem in the clinic that I want to look up-and I am rarely disappointed by what it says. This is a Rolls Royce of a textbook. There is a tendency to think of books as large as this one (particularly at a price of $£ 125$ even for the paperback) as suitable only for libraries. This would be a mistake. Despite its size and price this book's accessibility and comprehensiveness should make it the first choice as a postgraduate handbook, not only for psychiatrists but for neurologists and neurosurgeons too.

M Sharpe

\section{The parallel brain: the cognitive neuroscience of the corpus callosum}

Eran Zaidel, Marco lacoboni. Massachusetts: The MIT Press, 2003, pp 576, £61.95. ISBN 0262-24044-0

Roger Sperry's research on the cognitive abilities of split-brain patients following callosal section is a landmark in the study of brain-behaviour relationships. His studies firmly established the role of the corpus callosum in inter-hemispheric information transfer. What have we learned more recently about the role of the corpus callosum in cognition? In this book Eran Zaidel (originally one of Sperry's students) and neurologist Marco Iacoboni present 22 chapters based on a 1996 NATO Advanced Science Institute that attempt to answer this question. The central focus is on the classic problem of why reaction time to respond to a light flashed in either visual field differs according to whether the ipsilateral or contralateral hand is used to respond (known as the Poffenberger effect, after the psychologist who described it in 1912). This is thought to reflect callosal information transfer between the hemispheres; the book uses anatomical, physiological, and behavioural perspectives to address the question of what information is transferred and how the transfer might take place. Many chapters are accompanied by commentaries and editorial comment, giving a flavour of the debates and controversies in the field. Perhaps reflecting the long interval between the original conference and this book, more recent studies that use functional neuroimaging techniques to investigate callosal function are relatively poorly represented. However, there is still much of interest in this otherwise comprehensive volume. The chapters generally have a basic scientific focus, but chapters on multiple sclerosis, dyslexia and alexia, schizophrenia, and attention deficit hyperactivity disorder also contain much that will interest the practicing clinician.

G Rees

\section{Magnetic resonance imaging in stroke}

Stephen Davis, Marc Fisher, Steven Warach, eds. Cambridge: Cambridge University Press 2003, pp 266, £80.00. ISBN 0-521-80683-6

This book does much more than its title would suggest. Although mainly concerned with magnetic resonance imaging (MRI) in stroke, the text actually covers single photon emission computed tomography (SPECT) and positron emission tomography (PET) imaging as well and containing one of the best chapters ever written on computed tomography (CT) in stroke. The approach and content reflect the predominance of neurologists among the editors and authors, with only a few radiologists, and is really aimed at neurologists and stroke physicians.

The scene is set in the first chapter with a discussion of the limitations of clinical diagnosis of stroke and the specific role that imaging can play in diagnosing the type and cause of stroke. There is a superb chapter on CT in acute stroke, which exemplifies how the role of imaging in any diagnostic process should be evaluated. Separately, there is a chapter on CT evaluation of cerebral blood flow, a useful and practical introduction to MRI, discussion of conventional structural MR techniques such as T2, FLAIR, and gradient echo sequences, and a section on MR angiography. Much of the rest of the book (about half of it) is given over to diffusion and perfusion MRI, including its evaluation in animal models, concepts of identifying the ischaemic penumbra, evaluation of transient ischaemic attacks, selection of patients for new therapies and drug development trials, and finally a chapter on MR spectroscopy and a (very short) chapter on functional MR after stroke.

Although written by MR enthusiasts, the text is tempered with some discussion of the drawbacks of MR, such as poorer patient accessibility (compared with CT) and problems of metallic foreign bodies. It also makes the point that, despite the huge interest in MR diffusion and perfusion imaging, the precise thresholds of defining irreversibly damaged tissue and tissue at risk are yet to be determined. Some aspects of stroke MRI are not dealt with in much detail, for example classification or interpretation of white matter lesions (frequently found in stroke patients), or the identification and interpretation of microhaemorrhages on MR and how they might influence decisions regarding stroke treatment, or on using diffusion imaging to identify lesions in patients with milder strokes or at later time intervals after acute stroke (that is, not just the first few hours). There is very little on practical issues (perhaps reflecting the neurology rather than the radiology approach) such as how one assesses a stroke patient who is unable to speak prior to MR to make sure that it is safe for the patient to go into the magnet, and how one manages the patient while in the magnet with respect to factors such as oxygenation.

Some of the authors express personal views that not all readers will agree with. For example, in the chapter on assessment of a transient ischemic attack (TIA), the authors suggest that the definition of a TIA should be changed to one based on the presence or absence of certain imaging features. Although this clearly represents a personal opinion expressed by the authors, my objection to changing a classification that is so fundamental to stroke epidemiology and clinical practice is that only those with access to an MR scanner with diffusion imaging would be able to correctly diagnose a TIA using this new classification. Not only that, but the diagnosis of TIA might be dependent on the ability of the local radiologist or clinician to spot subtle features of recent ischaemia on diffusion, and on the timing of scanning after symptom onset.

I found it a little disappointing that a proportion of the perfusion images were presented in black and white when this is one technique which really requires colour display for proper interpretation and appreciation.

In summary, this is a useful textbook, particularly for neurologists or stroke physicians who need to understand more about imaging and its role in patient characterisation, decision making, and assessment of treatments in acute stroke. It's not just about MR and everybody with an interest in stroke should read the chapter on clinical efficacy of CT in acute cerebral ischaemia. At just over 250 pages it is easily digestible and yet also a useful reference. At $£ 80.00$ I think compared with other books on MR and on stroke it represents good value for money.

\section{J M Wardlaw}

\section{Cortex and mind: unifying cognition}

Joaquin M Fuster. Oxford: Oxford University Press 2003, pp 284, £47.95. ISBN 0-19514752-9

Joaquin Fuster is a distinguished American neuroscientist whose work has explored the neurophysiology of cognition, largely in animals, but with the ultimate goal of understanding how the human mind is implemented in the brain. His own research has focused particularly on the neuronal basis of working memory, revealing "memory" cells in the prefrontal cortex that help to retain the information an animal must "keep in mind" if it is to act appropriately after a delay-like the position of a covered well containing food. These prefrontal memory cells are a key component of an extensive cortical network required to maintain working memory, which also involves 
posterior brain regions closer to the sensory cortices, with a more traditional role in representing our surroundings.

Cortex and mind ranges far beyond the confines of Fuster's own experimental work. Its ambition is to describe how our key cognitive abilities-perception, memory, attention, language, and intelligence-emerge from the widely distributed cortical networks, or cognits in Fuster's terminology, which, he believes, represent the entirety of our knowledge. Fuster's interesting position is that interwoven and sometimes identical networks are involved in each of these cognitive functions, which are therefore far less well localised and less distinct than much of our contemporary quasi-phrenological thinking suggests: no cognitive function has a fully dedicated cortical area or network; conversely, a cortical network or representation is at the disposition of any and all functions.

This view has a good deal of appeal; perception is in part the reactivation of memory, attention is expressed in the changing content of perception, language and intelligence emerge from the categories that perceptual memory creates...and yet other observations, like the role of the medial temporal lobes in acquiring declarative memories, or of the fusiform gyrus in face perception or inferior parietal lobe in spatial awareness, seem to call for a more finely differentiated theory of cortical function than Fuster's general line of argument suggests.

Fuster's main thesis condemns him to repeat himself at times as he works through the roster of our cognitive functions, and he tends to a rather abstract style. But there is much fascinating information to be found here-I particularly enjoyed the closing chapters on language and intelligence-and anyone who is used to locating cortical functions on colourful scans will find cause for thought in these pages.

A Zeman

\section{The bard on the brain- understanding the mind through the art of Shakespeare and the science of brain imaging}

Paul M Matthews, Jeffrey McQuain. New York: The Dana Press 2003, pp 222, £24.50. ISBN 0-9723830-2-6

One of the great challenges of popular science writing is to convey a coherent and consistent impression of scientific ideas while avoiding confusing, specialist terminology. The most useful tools for this task are metaphor and pictures. The Dana Press, publisher for the Charles A Dana Foundation, has as its mandate "the provision of information about the personal and public benefits of brain research". With The bard on the brain, they have chosen to use the voice of William Shakespeare, the master craftsman of metaphor, to introduce the areas of human cognition that have attracted the most attention in recent functional imaging research. The logic behind this approach is that, as the authors explain, "Shakespeare's genius derives from his keen insight into the human mind" and that, in functional imaging, "brain scientists finally have the means to address questions that Shakespeare so eloquently put forward four centuries ago".

The book is a play in seven acts, each of which tackles a different field of research in cognitive neuroscience, including perception, language, the inner world of memory and emotions, and the breakdown of the mind in certain neuropsychiatric disorders. Within these acts, each scene examines a particular feature of the mind and illustrates how Shakespeare dissected and explored it in his own laboratory - the theatre. The scene opens with a quotation from a chosen play and a brief synopsis of the plot before moving on to discuss the hard neuroscience underlying this cognitive phenomenon as revealed by the latest neuroimaging techniques. For example, in discussing the role of the frontal lobes in attention shifting and the planning of behaviour, the example is chosen of Prince Hal, the wayward, youthful heir of Henry IV who purposely turns from the influence of Sir John Falstaff and his frivolous drinking companions in order to develop the resolve and strength of character which will later serve him well as King Henry V. This transformation is compared with the case of Phineas Gage, the 19th century rail worker who survived a dramatic penetrating injury to his cranium but consequently displayed a remarkable alteration in his personality. Recent computed tomography reconstructions of Gage's skull by Hannah and Antonio Damasio have clearly delineated the passage of the three foot tamping iron through the frontal cortex-the area "responsible for the functioning of what we call a moral sense".

The concept is an entertaining one and the authors have worked hard to bring it to life. The target audience presumably consists of people with no specialist knowledge of either Shakespeare or neurology and, if this is so, the reader will find plenty to hold his or her interest. The rich neuroscientific tableau ranges from Chomsky and language to the functional imaging of hallucinatory experience in schizophrenia, while the bite-sized chunks of Shakespeare successfully convey the bard's penetrating insight into the human psyche. The suggestion is that scientists, too, need to step outside the laboratory to find inspiration for their hypotheses. Lavish illustration with functional magnetic resonance imaging (fMRI), positron emission tomography, and single photon emission computerised tomography images, alongside numerous performance photos from well known theatre companies, give the book an enticing, coffee table appeal.

However, the book suffers from the contortions undergone in order to link the Shakespearian poetry to the scientific project. Take, for example, the use of Macbeth's grasping at an illusory dagger to introduce a discussion of the cerebellar control of complex motor acts, or the soliloquy from Hamlet's murderous uncle, Claudius, which begins "O, my offence is rank, it smells to heaven" as a cue to show fMRI pictures of "areas of the brain that become active with smell". In addition, the simplistic, rather than simplified, portrayal of functional imaging is coupled with brain images that are often unlabelled and poorly explained, giving the impression of a gaudy backdrop used to distract from an empty plot. The inherent danger in this approach is that, instead of facilitating public understanding of neuroscience, an aura of charmed infallibility is created. A brief mention of some of the limitations of functional imaging techniques would have helped to avoid this pitfall.

On balance, where this book succeeds, it does so due to the infectious enthusiasm of the authors. The tortuous metaphors and fancy pictures do not help much. Dialogue between science and literature has come a long way since CP Snow gave his famous Rede Lecture on the two cultures in 1950. Non-scientists are devouring popular science books-perhaps scientists need to reciprocate the attention. The Bard on the brain could certainly be instrumental in encouraging us to get to the theatre more often.

C Butler

\section{Parkinson's disease, diagnosis \& clinical management}

Stewart A Factor, William J Weiner. New York: Demos Medical Publishers 2002, pp 716, \$175.00. ISBN 1-888-799-50-1.

This multi-authored tome on Parkinson's disease (PD) admirably captures the complexity and diversity of the many clinical challenges and scientific problems that surround this common neurodegenerative disorder. Contributions over 58 chapters embrace an international body of expertise, with a pronounced north American emphasis, and range from discussing the early history of the condition to a welcome section on social issues, with in depth attention paid to the clinical presentation, including psychological features, structural and chemical pathology, theories of aetiopathogenesis, drug, surgical, and other treatments, and atypical and familial forms of parkinsonism. The text is generously referenced and well-illustrated with black and white figures. There are impressive chapters on the contribution of MPTP to our understanding of PD, genetic and environmental factors, and the drug classes employed in treatment as well as the complications of treatment, including dyskinesia and motor fluctuations. Proper attention is given to the management of psychosis and cognitive decline, with discussion of the relationship of these features in PD to dementia with Lewy bodies and Alzheimer type pathology. Future avenues of treatment, including neuroprotection and gene therapy, are also covered in this near encyclopaedic compendium, which is highly recommended for all those who treat patients with PD in neurology, geriatrics, and old age psychiatry departments, as well as research scientists in the field, and it should be required reading for all neurological trainees.

R Pearce

\section{Principles and practices of emergency neurology-handbook for emergency physicians}

S M Shah, K M Kelly. Oxford: Oxford University Press, 2003, pp 454, £40.00, (paperback). ISBN 0521009804

This is a handbook based on an earlier larger book, Emergency neurology: principles and practice, in response to enquiries from emergency medicine residents about whether a handbook, based on this main text, would be available. This is the result. Whether it is justified in calling itself a handbook is hard to say. The area covers three of my hands (small!). It runs to over 400 pages with approximately 50 authors. It covers neurological examination and neurodiagnostic 
testing, common neurological presentations, for example headache and weakness, specific neurological conditions, for example multiple sclerosis and cerebrovascular disease, neurological trauma, paediatric neurological emergencies, pregnancy related neurological emergencies, neurotoxicology, and brain death. So, it attempts a comprehensive coverage.

The editors consider it to be symptom based, although this is not always achieved. It has many tables, good illustrations, and management of algorithms with "pearls and pit falls" at the end of every chapter.

The neurological examination is done poorly, particularly the cranial nerves. This needs to be done with pictures of the lesions, their causes, and the anatomy, based around the common emergency presentations in A\&E. Although British neurologists would disagree with some of the advice given, most of the text is reliable and clear. (For instance, in the chapter on myasthenia gravis, it states "useful gauges include pulse oximetry, peak expiratory flow and PCO2 measurement", which are all poor gauges of impending ventilatory failure and vital capacity is the most important measurement in this respect.)

The most disappointing feature is that the chapters are not adequately focused on emergency conditions. The chapter on movement disorders covers virtually the whole spectrum of chronic movement disorders without specifically concentrating on the common acute presentations, such as drug induced dystonia with oculogyric crisis and hemiballismus, which are likely to come to A\&E. Unfortunately the editors and authors have failed to produce a sufficiently concise account of emergency conditions to make this book really useful. It needs to be much briefer and appropriately focused to achieve its aim and it would be better as a pocket book, similar to the edition of the Oxford text of medicine, which seems to occupy the pockets of most medical students! If only we could achieve the same for the pockets of medical SHOs in emergency neurology, things might improve!

D E Bateman

\section{Duchenne muscular dystrophy, 3rd edn}

Alan E H Emery, Francesco Muntoni. Oxford: Oxford University Press, 2003, pp 280, £79.50 (hardback). ISBN 0-19-851531-6

Quite simply, this monograph is essential reading for anybody involved with this devastating condition, and indeed for those involved with any form of muscular dystrophy, whether in the clinic or in the laboratory. Duchenne muscular dystrophy (DMD) is the archetypal dystrophy. It is because the clinical course is so stereotyped that it was the first of the dystrophies to be defined clearly, over a century ago. The historical journey from the first clinical descriptions to our present state of knowledge forms the core of this book, with side branches relevant to the identification of other specific forms of dystrophy, particularly the limb girdle dystrophies. The nihilist may suggest that all of this knowledge has as yet failed to find a cure, but for the clinicians intimately involved with these patients we can now do more than ever to provide an improved quality of life. There is of course great hope that "genetic engineering" will lead to a cure, but patients and their families cannot live on hope alone and Professors Emery and Muntoni have elegantly summarised present management options.

The second edition was published in 1986, a matter of months before the identification of the gene involved in the disease process and its protein product dystrophin. Within a few years it became apparent that dystrophin and dystrophin associated proteins have a fundamental role in various forms of muscular dystrophy, and for a while it looked as if there might be a common mechanism of membrane fragility due to dysfunction of these membrane associated proteins. Then abnormal cytosolic proteins were found in some forms of limb girdle dystrophy and it became clear that there was no simple single disease mechanism. Despite that, altered function of membrane proteins is clearly of fundamental importance in many dystrophies and Muntoni has been at the forefront of recent discoveries relating to altered glycosylation of the membrane protein $\alpha$-dystroglycan in various forms of congenital and adult onset limb girdle dystrophies.

There is no need to describe the individual chapters in detail. In brief, the monograph covers the history of the disease (Emery being a noted medical historian), clinical features, differential diagnosis, molecular pathology, pathogenesis, genetic counselling, and management. Emery is retired from clinical practice but the clinical setting is kept up to date by his being joined by Muntoni for this timely third edition.

All those involved in the management of DMD will find something of value in this book. Some patients and families may also want to dip into it. Those interested in the history of medicine, and the evolution of modern genetic and molecular techniques, will find it a fascinating story.

Let us hope that a fourth edition, detailing the successes of genetic engineering, will not be too far off, but in the meantime there is much that can be done to alleviate the consequences of this truly awful condition.

D Hilton-Jones

\section{Mental and behavioral dysfunction in movement disorders}

Marc-Andre Bedard, Yves Agid, Sylvain Chouinard, Stanley Fahn, Amos D Korczyn, Paul Lesperance. New Jersey: Humana Press 2003 , pp 543, \$185.00 (hardback). ISBN 158829-119-7

It was not long ago that the basal ganglia were confidently asserted to have no influence on cognition, and to have only motor functions. This was the province of neurology, and the concept that they might be involved in disordered behaviour other than that referred to as movement disorders was an anathema to generations of neurologists.

As Goetz notes, in the introduction to this nicely produced book, this view ignored over a 100 years' of clinical observation, and much subsequent work, theoretical, clinical, neurochemical, and neuroanatomical, all of which underline the central role of the basal ganglia structures in regulating behaviour, in its widest sense, and hence the association between movement disorders and cognitive and behavioural dysfunction.

The openers in this text are with neuroanatomy and neurochemistry, rightly so since the impact of the discovery of dopamine and the unveiling of the new neuroanatomy of the limbic forebrain, have fundamentally altered the way we think about the brain and its functions, and should profoundly influenced clinical thinking. A chapter on the cerebellum is also included in the opening section.

The book then contains chapters on two main themes, cognition in movement disorders, including the long controversial area of links with dementia, and the neuropsychiatry of movement disorders. The main diseases discussed are the obvious eponymous ones of Parkinson's, Huntington's, and Gilles de la Tourette, as well as corticobasal degeneration. There are some curious omissions, Wilson's disease, Sydenham's chorea, and supranuclear palsy, among others. The cognitive problems embrace such topics as speech disorders and apraxias, and include chapters on animal models as well as clinical research.

The section on neuropsychiatric aspects is laid out rather differently and less systematically. A chapter on mood disorders and the pallidum, another on depression and the basal ganglia, another on psychosis and mood disorders in Huntington's disease, some disease orientated, others anatomically based. Nevertheless, the individual chapters are, for the most part, well written, and included are contributions on REM sleep behaviour disorder, psychogenic movement disorders, and obsessive compulsive disorder. A separate section is devoted to quality of life studies.

The book is a timely reminder of the growth of interest in and the clinical importance of neuropsychiatry, and quite some space in the text is given to treatment and management issues. No longer can the basal ganglia simply be viewed as structures subserving motor function, they represent drives and affects which are re-represented cortically and which propel our very being.

M Trimble

\section{CORRECTIONS}

doi: 10.1136/jnnp.2003.029074corr 1

In the review by Rockwood in the May issue of JNNP (K Rockwood. Size of the treatment effect on cognition of cholinesterase inhibition in Alzheimer's disease. $J$ Neurol Neurosurg Psychiatry 2004;75:677-85) there is an incorrect entry on the $\mathrm{x}$ axis each of the tables in figure 1 . The sixth entry should read 0.25 , instead of 0.5 . The corrected table can be viewed at http://www.jnnp.bmjjournals.com/ cgi/content/full/75/5/677/DCl

\section{doi: 10.1136/jnnp.2003.034876corr 1}

The authorship list of the letter entitled emotion process in the minimally conscious state, by Bekinsctein et al (JNNP May 2004;75:788), was incorrectly printed as T Bekinschtein, J Niklison, L Sigman, F Manes, $\mathrm{R}$ Leiguarda, J Armony, A Owen, S Carpintiero, and L Olmos. However, the correct order is as follows: $\mathrm{T}$ Bekinschtein, $\mathrm{R}$ Leiguarda, J Armony, A Owen, S Carpintiero, J Niklison, L Olmos, L Sigman, F Manes. 